IZA DP No. 8099

Learning-by-Doing in a Highly Skilled Profession

When Stakes Are High:

Evidence from Advanced Cancer Surgery

Daniel Avdic

Petter Lundborg

Johan Vikström

April 2014 


\title{
Learning-by-Doing in a Highly Skilled Profession When Stakes Are High: Evidence from Advanced Cancer Surgery
}

\author{
Daniel Avdic \\ IFAU-Uppsala and $\mathrm{CINCH}$ \\ Petter Lundborg \\ Lund University and IZA \\ Johan Vikström \\ IFAU-Uppsala and UCLS-Uppsala University
}

Discussion Paper No. 8099

April 2014

IZA

P.O. Box 7240

53072 Bonn

Germany

Phone: +49-228-3894-0

Fax: +49-228-3894-180

E-mail: iza@iza.org

Any opinions expressed here are those of the author(s) and not those of IZA. Research published in this series may include views on policy, but the institute itself takes no institutional policy positions. The IZA research network is committed to the IZA Guiding Principles of Research Integrity.

The Institute for the Study of Labor (IZA) in Bonn is a local and virtual international research center and a place of communication between science, politics and business. IZA is an independent nonprofit organization supported by Deutsche Post Foundation. The center is associated with the University of Bonn and offers a stimulating research environment through its international network, workshops and conferences, data service, project support, research visits and doctoral program. IZA engages in (i) original and internationally competitive research in all fields of labor economics, (ii) development of policy concepts, and (iii) dissemination of research results and concepts to the interested public.

IZA Discussion Papers often represent preliminary work and are circulated to encourage discussion. Citation of such a paper should account for its provisional character. A revised version may be available directly from the author. 


\title{
ABSTRACT \\ Learning-by-Doing in a Highly Skilled Profession When Stakes Are High: Evidence from Advanced Cancer Surgery ${ }^{*}$
}

\begin{abstract}
Although learning-by-doing is believed to be an important source of productivity growth, there is limited evidence that production volume affects productivity in a causal sense. We document evidence of learning-by-doing in a highly skilled profession where stakes are high; advanced cancer surgery. For this purpose, we introduce a novel instrument that exploits the closure and opening of entire cancer clinics which have given rise to sharp and exogenous changes in the cancer surgical volumes at Swedish public sector hospitals. Using detailed register data on more than 100,000 episodes of advanced cancer surgery, our results suggest positive effects of surgery volumes on survival. In addition, we provide evidence on the mechanisms through which these improvements occur. We also show that the results are not driven by changes in patient composition or by other changes at the hospital level.
\end{abstract}

JEL Classification: I11, I12, I18, L11

Keywords: hospital volume, learning-by-doing, cancer surgery, survival, causal effect

Corresponding author:

Petter Lundborg

Department of Economics

Lund University

P.O. Box 705

22007 Lund

Sweden

E-mail: petter.lundborg@nek.lu.se

\footnotetext{
"We would like to thank Jerome Adda, Tabea Bucher-Koenen, Tomas Buchmueller, Christina Felfe, Lena Hensvik, Martin Huber, Per Johansson, Martin Karlsson, Martin Lundin, Nikolaj Malchow-Moller, Paolo Pertile and seminar participants at MEA-Munich, IFAU-Uppsala, University of St. Gallen, the University of Southern Denmark, Lund University, 12th Journées LAGV in Aix-de-Provence, Economics of Disease workshop in Darmstadt, Maastricht, University of Duisburg-Essen, CBSCopenhagen, University of Gothenburg, ESPE 2013 and EALE 2013. Financial support from the Swedish Council for Working Life and Social Research (DNR 2004-2005 and 2009-0826) is gratefully acknowledged. Vikström acknowledges support from the Tom Hedelius and Jan Wallander Foundation.
} 


\section{Introduction}

Learning-by-doing is believed to be an important source of productivity growth (Arrow, 1962; Lucas, 1988). The explanation for this is straightforward - the more individuals or organizations perform a specific task, the better they become at doing it. Evidence for learning-by-doing has been obtained by linking greater accumulated production volumes to reductions in unit labor costs or, more directly, to quality improvements in a variety of activities, including Kibbutz farming, ship building, car manufacturing, airplane flight control, nuclear plant operation reliability, iron works and even pizza making (Wright 1936; Lundberg 1961; Darr et al. 1995; Jovanovic and Nyarko 1995; Benkard 2000; Thornton and Thompson 2001; Thompson 2001; Levitt et al. 2012).

While it is widely believed that greater production volumes facilitate learning-by-doing, and thereby productivity, in almost all sectors of the economy, there is surprisingly little causal evidence showing that this is the case (Thompson, 2012). ${ }^{1}$ Estimating the causal effect of volume has proven to be difficult for a number of reasons. Perhaps the most obvious problem is that conventional measures of experience and tenure are likely to be correlated with unobserved factors which, in turn, are associated with productivity. Moreover, and as already noted by Wright (1936), a negative relationship may arise if the consequence of more tooling and the standardization of procedures is that a firm's ability to use less skilled labor increases. $^{2}$

In this paper, we focus on learning-by-doing in the health care sector. Apart from the general difficulties in estimating learning-by-doing effects, the specific case of the health care sector brings additional identification problems; first, differences in outcomes between high and low-volume hospitals may be explained by selective referral where high-quality hospitals have higher volumes simply because they attract more patients - i.e. a reverse causality mechanism. Secondly, individuals with different health characteristics may self-select into areas with different hospital sizes, such as rural and urban areas. Third, local health shocks, such as localized outbreaks of contagious diseases, affecting both hospitalization incidence and health outcomes, could induce a spurious relationship between the cumulated number

\footnotetext{
${ }^{1}$ This is in contrast to the extensive literature that shows how incentives affect productivity in a variety of settings, see, for example, Currie et al. (1995); Lazear (2000); Croxson et al. (2001); Hamilton et al. (2003); Gaynor et al. (2004); Bandiera et al. (2007, 2009); Acemoglu and Finkelstein (2008); Hossain and List (2009); Propper and Van Reenen (2010); Propper et al. (2010); Bloom et al. (2013); Clemens and Gottlieb (2014).

${ }^{2}$ In a recent overview of the literature, Thompson (2012) states that: "Unsurprisingly, since the much greater part of the empirical learning curve literature predates the wide use of instrumental variable techniques (Angrist and Krueger, 2001), the body of literature offering reliable support for the standard formulation is smaller than is generally supposed."
} 
of treatments and their outcomes. For policy purposes, while being observationally equivalent to learning effects, these competing explanations obviously have very different policy implications than those drawn from a learning-by-doing hypothesis.

The medical literature has tried to account for selection problems by controlling for observable patient characteristics such as age, gender, and reported health conditions. ${ }^{3} \mathrm{~A}$ notable contribution is Birkmeyer et al. (2003), who found a positive relationship between volumes and survival for cancer and cardiovascular surgery using a nationwide Medicare sample. In order to also account for unobserved heterogeneity across hospitals, some researchers have utilized longitudinal data to estimate fixed-effects models (Hamilton and Hamilton, 1997; Hamilton and Ho, 1998). ${ }^{4}$ The limitation of these types of models is that they only account for time-invariant unobserved heterogeneity across groups, whereas, e.g., selective referral may be driven by trends in hospital quality. To overcome such endogeneity concerns, two US-based studies have used the number of hospitals within a certain radius as an instrument for hospital volumes and applied instrumental variables techniques (Gaynor et al., 2005; Gowrisankaran et al., 2006). ${ }^{5}$ Since, the market structure in a health care system that allows for private providers is an endogenous outcome of a competitive process, the number of hospitals in an area is not necessarily exogenous. In such a setting, hospitals may base their entry and exit decisions both on underlying patient characteristics and on the current and expected volume and quality of existing hospitals in the same area. ${ }^{6}$

With the limitations of the existing literature in mind, we are able to provide new evidence of learning-by-doing by studying the causal effect of production volumes on quality outcomes in advanced cancer surgery. In order to deal with the endogeneity of production volumes, we introduce a novel instrument that generates quasi-experimental variations in the number of

\footnotetext{
${ }^{3}$ Halm et al. (2002) review 135 medical studies on the volume-outcome relationship for surgical procedures of which about 70 percent of the studies find a significant and positive correlation. In a summary article in the New England Journal of Medicine, Kizer (2003) concludes that the strongest link between volume and outcome has been found for AIDS treatment, pancreatic cancer, esophageal cancer, abdominal aortic aneurysms, and congenital heart disease.

${ }^{4}$ In neither of these studies were there any evidence of a causal volume-outcome relationship after controlling for hospital fixed effects, hence supporting the selective referral hypothesis.

${ }^{5}$ Gaynor (2006) finds positive effects of volume on survival following heart surgery using the number of hospitals offering CABG operating in a specific radius around the hospital of treatment in question as an instrument for surgical volume. Gowrisankaran et al. (2006) use hospital distance interacted with hospital and patient characteristics as an instrument and find positive effects of volumes on survival after heart surgery and the repair of an abdominal aortic aneurysm.

${ }^{6}$ Other studies have used the total number of hospital beds as an instrument for hospital volumes (Luft et al., 1987; Hughes et al., 1988; Farley and Ozminkowski, 1992; Norton et al., 1998). However, with selective referral it is likely that high-quality hospitals are both larger and have more beds. Finally, Tsai et al. (2006) and Kahn et al. (2009) use distance to a high-volume hospital for each patient as an instrument for the probability of getting treated at a high-volume hospital.
} 
cancer surgeries performed in Swedish public hospitals over the last two decades. Specifically, the proposed instrument exploits regional variation in closures and openings of entire hospital cancer clinics over time, which generate sharp changes in the surgical volumes performed at nearby cancer clinics. Importantly, since in-patient care in Sweden is organized by the public sector, we can be sure that the closure and opening of cancer clinics are not driven by market forces but rather by political decisions unrelated to hospital quality and underlying population health indicators - a conjecture supported by supplementary analyses of the data.

For the purpose of our study, we have collected detailed data on all breast cancer, prostate cancer and colorectal cancer surgical procedures performed at Swedish hospitals between 1998-2007 - in total more than 100,000 episodes. These three types of cancers constitute some of the major causes of mortality in the adult population. ${ }^{7}$ The data includes rich and detailed information about the type of surgery, date of hospital admission and discharge, prevalence of post-surgery complications and co-morbidities for each individual patient. Furthermore, we have linked the cancer surgery data to individual-level register data on mortality and socioeconomic characteristics.

We believe that cancer surgery is particularly well suited for studying learning-by-doing; first, the intuition for a causal volume-outcome is simple: practice makes perfect and the outcome of a surgical procedure is to a large extent dependent on the performance of the individual surgeon. Cancer surgery is also a complex procedure - the removal of tumors requires a high degree of individual skill — where even small mistakes might result in serious consequences for the patient's health, such as permanent impotence and urinary incontinence following prostate cancer surgery. A surgeon who has performed a large number of surgical procedures may have more finely developed skills and is better able to deal with potential complications during surgery as well as coping with heterogeneity in the patient population. Moreover, clinics performing large numbers of surgical procedures may also have better outcomes due to greater accumulated staff experience. ${ }^{8}$

Second, stakes are high in cancer surgery and critical decisions made by surgeons may have lethal consequences for the patient - the incentives to learn are therefore strong. Third, focusing on cancer surgery means that we are really able to focus on quality improvements

\footnotetext{
${ }^{7}$ For an overview of trends in cancer incidence and mortality, see, e.g., Cutler (2008) and Ferlay et al. (2013).

${ }^{8}$ This type of organizational learning was proposed already by Arrow (1962), who stated that "...it is the very activity of production which gives rise to problems for which favorable responses are selected over time.".
} 
in terms of survival following surgery. ${ }^{9}$ Moreover, we are able to study follow-up surgical procedures and re-admission prevalence as indicators of complications due to mistakes made during the initial cancer surgery. These indicators are also useful in the sense that they provide less dramatic health consequences in contrast to mortality outcomes. Such data on direct mechanisms has, with a few exceptions, been lacking in the previous literature.

Fourth, we test for heterogeneity in learning-by-doing by comparing results between different types of cancer surgery of varying degrees of complexity. This allows us to test the hypothesis of whether more learning takes place during more advanced tasks as compared to more trivial ones. As most of the general learning-by-doing literature has focused on learning in the manufacturing industry — which typically concerns manual labor - we are able to provide more insight regarding the learning process by estimating separate effects by complexity of the surgery.

Fifth, as an cancer surgery is normally planned months in advance we do not have to worry about the potential confounding influence of distance to nearest hospital in our analysis. This would be more problematic for more acute types of health events, e.g. acute myocardial infarctions, where any gains from learning due to the centralization of in-patient care may be offset by reduced health care access for patients living further away from a hospital.

Our focus on the Swedish public health care system brings some advantages for our empirical analysis. In this setting, we can rule out certain effects of mergers on the quality of outcomes that are not mediated through learning-by-doing. ${ }^{10}$ Importantly, in a competitive system, consolidation and mergers lead to reduced competition which may have a negative impact on the incentives to improve quality in order to attract patients. ${ }^{11,12}$ Thus, this effect has the opposite effect of learning-by-doing effects. In Sweden, patients are normally referred to a designated hospital (usually the closest one), leading to little competition between public hospitals in Sweden. For that reason we can rule out competition effects.

\footnotetext{
${ }^{9}$ Focusing directly on quality improvements helps to establish learning-by-doing compared to focusing on costs, since any negative relationship between costs and accumulated production can also be explained by the ability to use less and less skilled labor as more tooling and standardized procedures are introduced (Thompson, 2012).

${ }^{10} \mathrm{~A}$ related literature looks at the effects of hospital mergers on various outcomes, such as patient health, staff behavior, and costs, see for instance Ho and Hamilton (2000); Dranove and Lindrooth (2003); Currie et al. (2005); Harrison (2011); Gaynor et al. (2012a).

${ }^{11}$ Since US health care consumers face few differences in out-of-pocket expenditure across hospitals it has been suggested that the incentive is strong for hospitals to compete for patients on quality dimensions rather than on financial dimensions (Gaynor, 2006).

${ }^{12}$ For studies on the effect of hospital competition, see for instance Kessler and McClellan (2000); Propper et al. (2004); Volpp et al. (2005); Propper et al. (2008); Gaynor et al. (2011, 2012b).
} 
Focusing on the volume-outcome nexus in a public health care system is also of great policy relevance. Most existing evidence for learning-by-doing comes from competitive markets where organizational changes facilitating learning-by-doing mechanisms are likely to have been intentionally implemented and exploited by profit-maximizing agents. In the public sector, competition is often heavily restricted and regulations control market entries and exits - implying that efficiency-enhancing organizational changes are more likely to remain unexploited. In many countries, the health care sector is an example of such a heavily regulated market where stakes are at the same time high and in which efficiency gains can be counted in lives saved. Moreover, given the rapidly increasing health care costs experienced by many countries, there is a great need to identify the determinants of productivity in the health care sector. Clearly, evidence of learning-by-doing would have important policy implications, for example, with respect to health care concentration policies.

Our results suggest rapid gains of increased surgical volume. In our preferred IVspecification our results imply a death rate elasticity with respect to surgical volume of about 0.22 . Relating the size of this effect to the variation in hospital volume across hospitals in Sweden we find that increasing the volume of a given hospital from the 25th to the 50th percentile of the hospital volume distribution would imply an estimated decrease in cancer mortality rate with about 4.1 percentage points, or 18.7 percent. We also find that the learning effects increase with the complexity of the procedure - learning effects are greater for prostate and intestine cancer than for breast cancer. Moreover, we find that higher surgical volume reduces the probability of another cancer surgery. Given that multiple cancer surgeries for the same patient may indicate e.g. subsequent metastases that the surgeon may have missed when performing the initial surgery, we interpret this result as a surgeon learning effect.

We consider a number of threats to our IV-design. First, even if changes in volumes are exogenous you could argue that the estimated effect of volume on mortality runs not only through learning-by-doing but also through changes in patient characteristics. In particular, the exclusion restriction would be violated if the additional patients who after a closure are referred to a non-closed cancer clinic have a different underlying mortality risk than other patients treated at the same clinic. The estimated effect of an increase in volume may then also reflect a change in the composition of patients. We deal with this potential problem by i) including a battery of individual-level health indicators such as medical history and socioeconomic factors in order to capture heterogeneity in health and ii) by exploiting an institutional feature of the Swedish health care system in which individuals are assigned to a hospital based on their geographical location and not on choice. We are thus able to 
keep the underlying patient population constant by only studying the outcomes of those who belonged to the hospitals catchment area before the inflow of additional cancer patients from other catchment areas, ensuring that the population studied remains the same in terms of both observed and unobserved factors. The results are not affected when we impose this restriction.

Second, the exclusion restriction could fail if the closure or opening of cancer clinics cause more general organizational changes at the remaining hospitals. Any improved patient health outcomes at remaining cancer clinics could then be a consequence of these changes rather than increased learning in cancer surgery. If this were the case, we would expect patient outcomes to also be improved in other types of surgery at the same hospital - even in the absence of an increase in surgical volumes for these other types of surgery. ${ }^{13}$ We look for signs of such organizational changes by exploiting that the surgical volumes for other types of surgery other than cancer do not change when cancer clinics close at nearby hospitals. However, if increased volumes also correlates with, for instance, more resources for all types of surgery at the hospital level, we still expect a reduced form effect on the non-cancer surgery types. Utilizing information on another type of advanced surgery - cardiovascular surgery - we find that closures of nearby cancer clinics do not affect the volume of ischemic heart surgeries performed in remaining hospitals. Moreover, the reduced form effect of the closure of cancer clinics on the outcomes of heart surgeries is indistinguishable from zero, hence lending support to our exclusion restriction assumption.

Third, the closure and opening of cancer clinics may affect the technology used in the remaining cancer clinics as well as the composition of surgeons, which may have an effect over and above any learning effects from increased volume. By exploiting detailed data on surgical procedures and the technology used, such as robot-assisted surgery, we find no support for the former hypothesis. Moreover, by using linked employer-employee data from administrative registers we are able to show that changes in surgeon characteristics is an unlikely explanation for our estimated effects. In fact, we show that an increased operation volume, following the closure of nearby cancer clinics, does not lead to any significant increase in the number of surgeons at the remaining hospitals. Hence, this finding suggests an increased case load per surgeon subsequent to the cancer clinic closures.

Finally, closures and openings also affect the distance to the nearest cancer clinic for cancer patients. Even though we expect the distance to the nearest hospital to have less of an effect on patient outcomes for planned cancer surgeries, we collect data on the exact

\footnotetext{
${ }^{13}$ Note, however, that such a pattern could also arise if there are substantial productivity spillovers between clinics at the same hospital and may therefore not necessarily reflect a violation of the exclusion restriction.
} 
distance between an individual patient's place of residence and the nearest hospitals, and use this measure as an additional control in our regression model. As expected, controlling for changes in the distance to the nearest hospital does not affect our estimates.

To shed light on some of the mechanisms behind our estimated effects, we consider nonlinearities in the estimated volume-quality relationship with respect to the existence of a learning threshold, as is often found in the general learning-by-doing literature. Specifically, surgeons in low-volume hospitals may gain important experience from each additional surgical procedure they perform while, at larger hospitals, surgeons may already have had the opportunity to gain experience through a large number of surgical procedures. ${ }^{14}$ In order to study the non-linear effects in more detail, we complement the IV-analysis with a hospital fixed-effects analysis, relying on within-hospital changes in volumes over time. Our estimation results suggest that the volume effect is more prominent for lower surgical volumes whereas for larger volumes there are practically no volume effects at all, hence supporting the hypothesis that learning-by-doing is relatively more important at lower levels of surgical volumes.

To sum up, our paper contributes to two strands of the literature. First, we contribute to the general literature on learning-by-doing by providing new evidence of a causal relationship between production volumes and product quality as well as on the possible mechanisms through which this effect is mediated. Moreover, we contribute with implications for health care policy as our results largely imply that health care consolidation in the context of the public health care sector may lead to important health gains. This is an important finding, not least with respect to the particular institutional setting we have studied, as a large number of hospitals in our data operates below the empirical learning threshold we have identified.

The remainder of the article proceeds as follows: Section two outlines the basic characteristics of the types of cancer surgery in our study, with a particular focus on the scope for a learning-by-doing effect. Section three describes the data we use for estimation and section four provides relevant information on the institutional features of the Swedish health care setting and the rationale for why this particular context provides us with plausibly exogenous variations in hospital volumes. Section five presents the results from our main analysis of the effect of operation volumes on cancer survival along with a number of robustness checks to test the sensitivity of our results. Section six discusses potential mechanisms of the estimated

\footnotetext{
${ }^{14}$ One may also argue that increased hospital volumes below a certain point could have a negative impact on hospital quality. This would be the case if too high volumes lead to less efficient information channels, less efficient decision-making, exhausted medical staff and greater coordination problems.
} 
results supplemented with empirical analyses in order to assess these mechanisms. Finally, section seven concludes with a brief discussion about the policy implications of our results.

\section{Cancer surgery and Learning-by-doing}

In our analyses, we focus on the three most common cancer types of the Western world, i.e. breast, prostate and colorectal cancers. Prostate (breast) cancer is the most common type of cancer among men (women) in Sweden, accounting for 37 (30) percent of cancer incidence in 2003. Colorectal cancer is the second most common type of cancer for both sexes, constituting about 11 percent of all cancer diagnoses in the same year (Socialstyrelsen, 2007). In general, cancer operations are a common surgical procedure and require highly skilled medical staff in order to be performed.

Breast cancer is commonly diagnosed via triple assessment consisting of a physical examination, mammography/ultrasound and a biopsy. The biopsy usually includes sentinel node biopsy (SNB) where the sentinel node - the first breast lymph node to which cancer cells are most likely to spread - is diagnosed for cancer. After diagnosis, surgical treatment of the cancer may be performed through either a partial, full or a modified radical mastectomy depending on factors such as the size and spread of the tumor and the diagnostic results from the SNB. A partial, or breast-conserving, mastectomy is preferred due to its relatively low invasiveness while a full or radical mastectomy is performed for more complicated and aggressive cancer types. We include all three types of surgery in our analysis.

The surgical treatment of prostate cancer normally involves removing the entire prostate gland via a radical prostatectomy. We include the two most common types of radical prostatectomy: the retropubic and the endoscopic prostatectomy. The procedures differ according to the type of strategy the surgeon uses in order to access the tumor - in the retropubic prostatectomy the surgeon makes a large incision in the abdomen (so-called open surgery), while in the endoscopic prostatectomy several small incisions are made in order to insert surgical instruments into the body (so-called minimally invasive surgery). The latter is also called a laparoscopic prostatectomy due to its common use of a laparoscope for visualization and can be performed either manually or with the assistance of a robot. We also include in the analysis two additional palliative surgery procedures aimed at slowing down the progression of the disease. One is an orchidectomy which involves surgically removing one or

both testicles in order to reduce the amount of testosterone in the body which increases the progression of cancer, and the other a transurethal resection of the prostate (TURP) in which a part of the prostate gland is planed away using a resectoscope in order to facilitate 
urination for end-of-life patients.

Approximately two-thirds of all colorectal cancers in Sweden are colon-situated while one-third are located in the rectum. We include the three most common colorectal surgeries from each type in our analysis. The specific procedures of each colorectal cancer type is typically chosen depending on where in the intestine the cancer is situated. For rectal cancer, a low anterior resection (LAR) is performed if the cancer is situated in the upper third part of the rectum while an abdominoperineal resection is typically performed if the tumor is located closer to the anus. While the former procedure usually allows for a so-called anastomosis in which the bowels are sewn together again after surgery, the latter normally results in a colostomy - an opening in the skin of the abdomen to provide a channel for body feces to leave the body. A surgical resection of the rectosigmoid colon, known as the Hartmann's procedure, is sometimes also performed in acute cases when there is no possibility of reconnecting the bowels after surgery. In latter years the procedure known as a total mesorectal excision (TME) has become popular in surgery relating to the lower two-thirds of the rectum, replacing abdominoperineal resection surgery due to both lower cancer recurrence rates but also the possibility of avoiding a permanent colostomy as the procedure involves a reconstruction of the rectum. For colon cancer the typical surgical procedure is to perform a colectomy in which a part of the colon is removed and then reattached. Specifically, we include the right and left hemi-colectomy, referring to the resection of the ascending (right) or the descending (left) colon, respectively, and the sigmoidectomy, involving the resection of the sigmoid colon.

\subsection{Individual and organizational learning-by-doing}

Even with general treatment guidelines, surgeons have a great deal of discretion regarding the choice of the type of surgical procedure and how to apply it for each patient, for example, deciding how much tissue to remove (or margin to keep). Clearly, this involves making important trade-off decisions, not only before but also during surgery, as information available regarding the tumor is incomplete and constantly updated. Hence, there exists obvious scope for individual skill in the execution of successful treatments, not only in terms of survival, but also in other aspects of post-operative patient health such as surgery complications and tumor recurrences.

Based on the discussion above, it would not be far-fetched to argue that individual skill might be related to surgical experience - since cancers and human beings are heterogeneous by nature. Performing a greater number of surgical procedures should increase the probabil- 
ity of a previously encountered cancer type showing up again, which, in turn, could reduce initial information deficiencies regarding the particular characteristics of the disease.

Similarly, organizational learning-by-doing may arise from learning and experience gained at the organizational level. Surgeons performing surgery are assisted by a team of nurses, other specialists (e.g. gynecologists, radiologists, plastic surgeons and orthopedists) and need proper equipment and space. If the organizational environment at the clinic or hospital is poor, for example, if surgery teams are badly composed, this will also inhibit the surgeon's individual performance. Hence, greater experience may potentially lead to improved cooperation in such teams as the organization may learn over time who works well with whom. All in all, we believe that there is a clear potential in cancer surgery for both individual and organizational learning-by-doing in isolation of each other as well as possible interaction effects between the two processes on patient outcomes.

\section{Data}

Our primary data sources consist of the Swedish National Patient Register (NPR), containing population-wide information on all in-patient care in Sweden, and the National Causes of Death Register (NCDR), containing information about all deaths of individuals with their permanent residence in Sweden. The NPR contains individual-level data on the date and the hospital of admission and discharge, the nature of the admission such as the length of stay and whether it was acute or planned as well as rich medical information including main and co-diagnoses (through the International Classification of Diseases, ICD) and information about any medical procedures made in relation to the hospitalization (through the National Classification of Surgical Procedures, NCSP ${ }^{15}$ ). The NCDR includes information on the date, place and underlying cause of death. For both registers we have access to data until 2011.

As a major revision of the NCSP in 1997 made comparisons of procedures over time difficult, we chose to sample cancer surgery from 1998 and onwards. Furthermore, we set 2007 as our last sampling year in order to have at least a four-year follow-up period for each patient to evaluate surgical quality. As mentioned previously, we focus on breast, prostate and colorectal cancers and select the three most common surgical procedures within each category. Specifically, as some of the surgery procedures may also be performed for other diseases than cancer (e.g. a TURP for prostatic hyperplasia) we restrict our sample to

\footnotetext{
${ }^{15}$ The NCSP consists of fifteen main chapters containing operations according to the organ system, four sub-chapters, and a chapter with additional codes. The Nordic Medico-Statistical Committee (NOMESCO) published the first printed edition of the NOMESCO Classification of Surgical Procedures (NCSP) in 1996.
} 
individuals that had a cancer diagnosis at the time of hospitalization.

As our main outcome variable, we use survival four years after surgery, constructed using the exact dates of hospitalization and death. Using the information in the NPR, we additionally construct a number of other quality-related health outcomes such as readmission prevalence, multiple cancer surgeries and the number of days spent in hospital.

Table 1 presents sample statistics of the three cancer types included and the corresponding surgery procedures. Our sample consists of in total 109,761 observations of which 48 percent are breast cancer operations, 28 percent are colorectal cancer operations, and the remaining 24 percent are prostate cancer operations. The table also indicates a slight increase in the number of surgical procedures and a substantial decrease in the four-year mortality rate over time. On average, 39 percent of the patients in our sample die within four years after having undergone surgery. The four-year mortality rate is highest for colorectal cancers (56 percent) and lowest for breast cancer (28 percent). Finally, breast cancer patients are on average substantially younger than colorectal and prostate cancer patients.

\section{Empirical strategy}

\subsection{Descriptive background}

Before presenting our empirical strategy in more detail, we illustrate the variation we use in our data graphically. The lefthand figure of Figure 1 plots the raw correlation between the annual number of cancer surgical procedures and the four-year survival rates for each hospital and year. Each dot in the figure corresponds to the average survival rate for a given hospital-year combination. The smoothed average, estimated from a local polynomial regression and indicated by the solid line in the figure, shows that survival rates are higher for hospitals which perform more surgical procedures annually. This observed pattern is in accordance with a learning-by-doing hypothesis. However, the positive volume-outcome correlation visible in the descriptive figure could clearly also be explained by other mechanisms, such as patient or staff selection from e.g. selective referrals or selection in the underlying case-mix of patients in the catchment areas of small and large hospitals.

The righthand figure of Figure 1 describes our data from a more traditional learning-bydoing outset. Specifically, the figure evaluates the existence of a learning curve by plotting the relationship between cumulated surgical volumes and survival rates. ${ }^{16}$ Each dot in the

\footnotetext{
${ }^{16}$ Accumulated volume is defined as accumulated volume from 1998 onwards due to the changes in NPR coding that occurred in 1997 (see the data section).
} 
figure corresponds to the average survival rate as a function of cumulated volume in bins of ten surgical procedures, pooled over all hospitals and years. Interestingly, we see from the figure that the average survival probability increases substantially with cumulative hospital volumes, again suggesting a pattern that is consistent with a learning-by-doing mechanism. However, this analysis does not consider the influence of other confounding factors such as time trends for general surgical improvements, serially correlated health or cost shocks affecting both the number of procedures and changes over time in hospital quality and selective referral.

Thompson (2012) concludes in his overview of the learning-by-doing literature and the problems of identifying such effects that: "The solution, of course, is to find settings in which cost shocks do not induce changes in input use, or to find instruments for cumulative output.". In the remainder of the paper we continue our empirical investigation by applying such an instrument, hence shifting focus from discussing general volume-outcome associations towards making causality claims.

\subsection{The instrument}

In order to motivate our instrument we first provide some relevant background information on the Swedish health care system. In contrast to the U.S., the health care sector in Sweden is highly regulated and the vast majority of hospitals are owned and run by the public sector. Moreover, inpatient health care is organized and mainly financed at the regional level. Sweden is divided into 21 regions, Stockholm being the largest (about 2 million inhabitants) and Gotland the smallest (about 60,000 inhabitants). Organizing health care is the single most important responsibility for the regional authorities. For instance, in 2012 about 82 percent of the regional budgets were used for health care.

The regions in Sweden are run by a political council, elected every fourth year. Besides following some general laws and guidelines set by the government, e.g., that health care must be provided to all citizens, the regional authorities are more or less free to organize the health care in their region. In effect, since the hospitals are almost exclusively run by the public sector, the members of the regional board have a great influence in deciding the specific organizational features of the regional health care system - in particular the degree of centralization.

We exploit the fact that the substantial regional autonomy of the Swedish health care system leads to very different responses to the general health care centralization trend which took place in the early 2000s. Specifically, the central government passed a law in 2000 
stipulating that the regional councils were no longer allowed to run budget deficits. A consequence of this law was that many regions started discussing and proposing centralization measures in order to cut costs and increase efficiency, but, due to the different outcomes of the political negotiations, these proposals were only implemented in some of the regions (Lindbom, 2013; Larsson Taghizadeh, 2009). In this paper, we utilize the closure of cancer surgery clinics generating discontinuities in the number of cancer surgical procedures at remaining nearby hospitals within the same region across time. Applying these closures ensures that we utilize volume changes derived from political processes rather than surgical volume swings caused by regional health shocks, patient sorting and case-mix selection in hospital catchment areas. Moreover, as we have access to very detailed data stretching over a long period of time, we are able to perform extensive robustness checks to validate that the closures provide us with exogenous variations for our purpose. ${ }^{17,18}$

Using the NPR we define a cancer surgery clinic as closed (open) if the total number of procedures is two or fewer (greater) over three consecutive years. With this definition we obtain seven closures and two openings during our study period. The two openings constitute two formerly closed hospitals that were re-opened. To supplement the data we also validate the closures/openings using information obtained from local newspapers and political protocols.

In order to illustrate the variation we use, the lefthand figure of Figure 2 displays an indexed measure of the number of cancer surgical procedures performed at the closed clinics before and after the closure. Clearly, there are striking drops in the number of operations performed during the closure years. Moreover, the righthand figure of Figure 2 illustrates how the closures affect remaining nearby clinics in terms of surgical volumes - i.e. the first step of our proposed IV strategy. Specifically, the figure plots the difference in hospital volumes between remaining hospitals in regions with closures and hospitals in regions without any closures. For non-closing regions, the year of closure represents the year a clinic potentially could have closed in the region - i.e. a placebo closure. ${ }^{19}$ The closures evidently implied a substantial increase in the number of surgeries at nearby, remaining, hospitals in the region (on average about twenty percent) in contrast to non-closing regions.

\footnotetext{
${ }^{17}$ We are also able to rule out competition effects that are important in some other health care markets (see e.g. Bloom et al. (2011)). The reason is that patients in Sweden are normally referred to a designated hospital (usually the closest one) so that competition between hospitals is essentially non-existent.

${ }^{18}$ Note that we only consider closures of cancer surgery clinics - not entire hospitals - which means we can rule out any general merger effects. Moreover, recent evidence in Gaynor (2006) suggests limited merger effects.

${ }^{19}$ Since the first and last closure in our data occurred at the beginning and the end of the sampling period, respectively, the difference can only be displayed two years before and after the potential year of closure.
} 
Our empirical strategy using openings and closures would be invalidated if the political processes leading up to the closures and openings were influenced by demographic changes such as urbanization, business cycle effects or underlying trends in public health and/or in the population mix. In order to explore this potential threat to identification, Figure 3 plots key economic and health variables for regions with at least one opening or closure and unaffected regions, before and after the change took place, respectively. The figures reveal that regions affected by a hospital closure or opening on average have larger populations and higher average morbidity than the corresponding unaffected regions. However, we find no differences in unemployment, share of cancer hospitalizations and cancer mortality.

Due to these group differences in observable characteristics we include hospital and calendar time fixed effects and regional linear time trends in the analysis. ${ }^{20}$ Including these controls ensures that the variation provided by our instrument will be exogenous unless the timing of the openings/closures are correlated with underlying non-linear time trends from unobserved factors. As is evident from Figure 4, showing a plot of the residuals obtained from this regression, there is now no evident differences between the two groups. ${ }^{21}$ Hence, this supports our empirical strategy.

The remaining threat to our instrumental variable approach concerns the potential existence of any direct effects of the closures on our outcomes of interest - i.e. whether the closures affected the surgical quality at the remaining cancer clinics through other mechanisms than through changes in operation volumes. To investigate this possibility, we collect additional data and perform a series of specification checks. In particular, we test whether the closures systematically affected the case-mix in the remaining cancer clinics, since these clinics now had to take on a number of additional new patients. A change in the case mix would be problematic if the new patients treated at the remaining clinics had different underlying health characteristics compared to other patients. For this reason, we run regressions where we exclude the additional patients from our analysis and only focus on the patients that belonged to the remaining clinics' catchment area before the increase in volume. Importantly, in this case-mix adjusted analysis we exclude individuals treated at closed clinics both before and after the closure. Hence, systematic hospital closures arising from, e.g., different health care quality trends across closed and remaining cancer clinics are by definition not a problem in this analysis, since closed units are entirely excluded from the analysis.

\footnotetext{
${ }^{20}$ As a robustness analysis we have also estimated models with linear hospital trends instead of regional trends, resulting in practically unchanged estimates.

${ }^{21}$ For ease of comparison we have added the variable means to the residuals.
} 
Moreover, to assess the exclusion restriction further we; i) examine whether hospital surgery staff change their procedures (by, e.g., changing type of surgery) as a response to the additional inflow of new patients; $i i)$ test for effects from potential organizational changes coinciding with a closure or opening using data on other type of surgical procedures unaffected by the cancer clinic closures; iii) collect data on the exact distance from each patient's place of residence to all hospitals in order to examine whether hospital distance affects surgery outcomes; and $i v$ ) track all surgeons at hospitals where a cancer clinic closed in order to investigate to what extent the composition of surgeons changed in the remaining hospitals after the closure.

\subsection{Econometric model}

We specify a linear probability model for the probability of surviving at least four years after cancer surgery. Formally, our baseline model for survival of individual $i$ undergoing surgery $s$ at hospital $h$ in calendar year $t$ is:

$$
y_{i h s t}=\lambda_{t}+\lambda_{h}+\lambda_{s}+\gamma \log \left(\text { volume }_{h t}\right)+X_{i} \beta+\epsilon_{i h s t}
$$

Here, volume vit $_{\text {is }}$ the number of total cancer procedures performed at hospital $h$ in calendar year $t$. This baseline model controls for general time trends through calendar time fixed effects $\lambda_{t}$, general differences between different hospitals through hospital fixed effects $\lambda_{h}$, and differences across type of surgery through surgery fixed effects $\lambda_{s}$. A set of individual characteristics $X_{i}$, such as gender, age, level of education and pre-surgery health factors such as the number of previous hospitalizations and time since last the hospitalization, is also included in the model to account for individual heterogeneity in survival probability. Finally, we also include region-specific linear time trends in the model. ${ }^{22}$

We initially follow the traditional medical literature and estimate (1) by OLS. We then proceed by estimating FE-IV models applying the first-stage equation

$$
\log \left(\text { volume }_{h t}\right)=\alpha_{t}+\alpha_{h}+\delta D_{r t}^{\text {closure }}+u_{\text {ihst }} .
$$

where our instrument, $D_{r t}^{\text {closure }}$, is implemented as an indicator variable, taking the value one if a cancer surgery clinic in region $r$ closed in year $t$ or earlier. ${ }^{23}$ This captures the idea that

\footnotetext{
${ }^{22}$ The health variables are constructed using the data on hospitalizations presented in the data section and the socioeconomic variables are constructed using data from Statistics Sweden on the entire Swedish working age population. For older individuals we use the latest available information.

${ }^{23}$ Similarly, if a clinic is re-opened the closure dummy takes the value zero in the re-opening year and all
} 
closures generate a shift in surgical volumes at the remaining clinics in the region. Initially, we estimate the model in (2), with a single closure dummy. This restricts the volume effect to be the same in all regions, which is restrictive for several reasons. One reason is that in one region two cancer clinics were closed at the same time. Another reason is that in some regions rather large clinics were closed, while in others a smaller clinic was closed. We utilize these differences by specifying separate closure dummies for each region with at least one closure. This unrestricted version of the instrument captures the idea that effects on the remaining hospitals' volumes may differ across regions, for instance, depending on the size of the closing clinic and the number clinics that are closed.

The model in (1) is a restricted version of the standard power law formulation of learningby-doing models, since in (1) only current volume and not cumulative volume affects current quality. ${ }^{24}$ In order to investigate the learning dynamics in more detail, we replace current volume in (1) with cumulated volume in a subsequent analysis. We explore experience in the last year, last two years and full cumulated volume from 1998 and onwards. ${ }^{25}$ In these analyses we use lagged versions of our instrument in order to instrument for cumulated volume. The intuition is that the volume shifts induced from the closures cumulates over time as the surgeons gain additional experience for each year after the closure occurred. However, this elaborate analysis stretches the limit of what can be estimated using the variation created by closures and openings, which is also why we mainly focus on the effects of the current volume in the results section.

\section{Main results}

We begin this section by presenting results on the raw volume-quality relationship, estimated from a simple bivariate regression of hospital volumes on the four-year survival rate. As seen from column 1 of Table 2, there is a strong and significant volume-quality association in our data. The estimate implies that a hospital performing twice as many cancer surgical procedures as another hospital has on average about 5.7 percentage points higher four-year survival rates.

We next turn to our instrumental variables strategy. Column 2 of Table 2 presents the first-stage estimates for our instrument when the closure effect is restricted to being

subsequent periods.

${ }^{24}$ See e.g. Thompson (2012) for a discussion of various organizational learning models.

${ }^{25}$ Since the code classification changed in 1997 , we are not able to track volumes further back than that year. 
homogeneous across regions. The estimated coefficient on the closure indicator from equation (2) is statistically significant and positive, indicating that the closure of a cancer surgery clinic increases the average number of procedures performed at the remaining nearby clinics in the region. The standard errors are clustered at hospital level since we estimate individual level effects using variation at the hospital level. ${ }^{26}$

Next, consider the baseline IV estimate using the restricted IV model presented in column 3 of Table 2. The estimated coefficient suggests a sizeable, but not statistically significant, effect of surgical volume on the four-year survival rate. In Column 4 we switch to the unrestricted version of our instrument. The more flexible use of the closure instrument results in a reduction of the standard error of the volume effect estimate by more than 50 percent. The effect is now highly significant. The F-statistic is 29.3 , and this shows that we have no problems with weak instruments. Table 2 also presents estimates from additional IV specifications using the unrestricted version of our instrument. As patients treated at different hospitals may be heterogeneous with respect to health we add a set of individuallevel covariates to the model in column 5. The inclusion of these factors leaves the IV estimates practically unchanged.

In the last column of Table 2 we also condition on unobservable changes in the case-mix of cancer patients by re-estimating the model on a restricted sample, including only individuals belonging to a remaining hospital's catchment area prior to the closure. The intuition is the following: while we include these additional patients when predicting hospital volumes in the first stage equation (our surgical volume measure includes all types of surgery) we subsequently exclude them in the structural equation. Note that these individuals still contribute when calculating volumes, since surgeons also learn from these procedures. ${ }^{27}$ Excluding patients from closing hospitals has little effect on our volume effect and from this we conclude that our main effects are robust to unobservable changes in the patient case-mix. $^{28}$

The estimate from our preferred model in the last column of Table 2 implies that doubling the per annum number of surgical procedures at a hospital will on average increase the survival rate with 4.8 percentage points. The average four-year mortality rate in our sample is 0.22 so that the death rate elasticity with respect to surgical volume is about 0.218 , which

\footnotetext{
${ }^{26}$ We have also estimated standard errors clustered at regional level and multi-level standard errors clustered at both hospital and regional level. This exercise shows that clustering at hospital level renders the most conservative inference.

${ }^{27}$ See section three for a discussion on how patients are assigned to hospitals. Descriptive sample statistics show that $86 \%$ of the cancer surgery patients are treated at their designated hospital.

${ }^{28}$ We have also re-estimated the case-mix adjusted model using volume in levels instead with essentially the same results.
} 
we regard as a sizable effect. Moreover, relating the estimated effect to the sample variation in hospital surgical volumes, we find that increasing the volume of a hospital from the 25th percentile to the 50th percentile of the volume distribution (i.e. from 70 to 130 procedures per annum) would decrease the four-year mortality rate with about 4.1 percentage points, or 18.7 percent.

Our preferred IV estimate is, while not significantly so, somewhat smaller than the OLS estimate. When interpreting this difference it is important to keep in mind that some factors may bias the OLS estimate upwards and others may bias the estimate downwards. For example, a selective referral story in which high-quality hospitals have a higher volume simply because they attract more patients would imply the former bias, while selective referral in which more severe cases directed to large hospitals will imply the latter bias. Moreover, any sorting of patients into areas with varying hospital sizes will also bias the OLS estimate but in an a priori unknown direction. Finally, an additional possibility is that the IV estimate captures a LATE effect, i.e. the effect on a subset of the hospital volume distribution.

\subsection{Learning to avoid mistakes}

While an increased survival probability is likely to be the most important outcome for cancer patients, other important post-surgery outcomes such as subsequent complications are also meaningful quality measures. Moreover, such measures offer an opportunity to study learning effects directly, since an increase in learning should lead to fewer complications and fewer re-admissions for additional cancer surgery. ${ }^{29}$ In order to study complications, we use data from the hospitalization records and construct detailed information on re-admissions and subsequent cancer surgery. If surgeons can lower re-admission and re-operation incidence rates with additional experience, this suggest that greater volumes lead to experience gains and fewer mistakes in surgery.

Specifically, we estimate our preferred IV model using the probability of a re-admission within one year and a new cancer surgery within three years from the initial surgery as

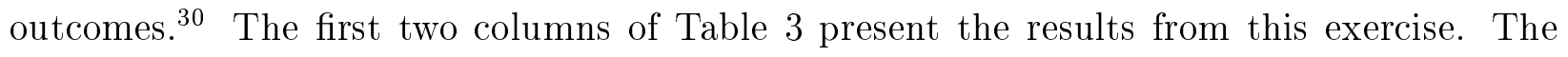
estimate from column 1 suggests a statistically significant reduced probability of subsequent

\footnotetext{
${ }^{29}$ Note, however, that since the level of invasiveness of the surgical procedure performed may be inversely related to survival probability, survival prospects and post-surgery life quality may sometimes be traded off against each other.

${ }^{30}$ We have also used other follow-up time periods for the re-admission and re-operation measures which give similar results.
} 
cancer surgery within three years from the initial surgery. In particular, if hospital surgical volumes are doubled, then, on average, the probability of another surgery decreases with about 0.034 . With a mean sample probability of follow-up cancer surgery of 0.08 , this translates into a sizable effect. ${ }^{31}$ Finally, the re-admission point estimate also has a negative sign, however indistinguishable from zero at standard levels of significance, which also points in the direction that learning-by-doing not only affects the survival dimension of health care quality but also other aspects of post-surgical life quality.

\section{Alternative interpretations}

Our results so far suggest beneficial effects of an increase in operation volumes. While these effects can be interpreted as learning in cancer surgery, there are other interpretations as well. Below, we consider a number of such alternative interpretations.

\subsection{Organizational changes}

If the closure of cancer clinics leads to more general organizational changes at hospitals with remaining cancer clinics, this could bias our volume estimate if such changes have a direct impact on the survival rate following cancer surgery. We investigate this by using data on other types of advanced surgical procedures which were not affected by the cancer clinic closures. Specifically, we utilize in-patient data on the most frequently performed heart surgeries, arguing that outcomes following these closely related types of procedures should also be affected by any general organizational changes, but that the mechanics of this effect would not run through any changes in volumes (since volumes should be unaffected by the closure of a cancer clinic). Thus, we effectively force the reduced form effect to only include potential direct effects from the closures and not the indirect volume effects from the first stage. Re-estimating the reduced form model using our closure instrument on heart surgery will thus act as an informal test of whether any important organizational changes at the remaining hospitals coincided with the increase in the volume of cancer operations.

The last two columns of panel A of Table 4 present the first-stage and reduced form estimates from our model only on heart surgeries while the first two columns report the baseline cancer surgery results for comparison. The first-stage estimate using cancer clinic

\footnotetext{
${ }^{31}$ These estimates suffer from a competing risk problem since deceased patients cannot undergo additional surgery. However, since we find that higher volumes increase the survival probability then, if anything, our estimates should be biased towards zero.
} 
closures as an instrument for heart surgery volumes is small and insignificant indicating, as expected, that the instrument is irrelevant for this particular sample. Moreover, the reduced form estimate is also insignificant and close to zero, implying that there is no direct effect of the closure of cancer clinics on the probability of surviving heart surgery. On the other hand, both the first stage and the reduced form estimates are significant for the cancer sample. Taken together, we interpret these results as evidence for the absence of any important general hospital organizational changes that coincided with the cancer clinic closures, which would have violated our exclusion restriction.

\subsection{Staff}

The closure of a cancer clinic could lead some surgeons to transfer to other hospitals or to become unemployed. At the same time, clinics with a greater inflow of patients may recruit new surgeons in order to meet the increased number of patients. If a large share of the surgeons at closed-down clinics are recruited to other clinics within the same region, our exclusion restriction might be violated because of staff compositional changes at the remaining clinics. Thus, the estimated positive effect of volume on survival might reflect the fact that the new surgeons recruited to the remaining clinics are more skilful. To address this concern, we have gathered information on surgeons employed at hospitals which shut down their cancer clinics in order to check to what extent these surgeons migrated to nearby hospitals in the region. To this end, we use the Swedish employment register, providing annual information on all hospital employees. Together with information on attained levels of education from a Swedish population register called LOUISE this allows us to identify surgeons at all hospitals and to follow them over time as they switch jobs. Moreover, the data also provides background characteristics of each individual. ${ }^{32}$

We focus on all surgeons at hospitals where a cancer clinic has been shut down, distinguishing between surgeons staying at the same hospital and surgeons transferring to other hospitals. In the first row of panel A of Table 5, we see that 69 percent of all surgeons who were employed at a hospital one year before the hospital closed its cancer clinic remained at the same hospital after the closure occurred. In contrast, 18 and 13 percent of the surgeons transferred to hospitals within and outside the region respectively in the year of the closure. In total, however, the transferring surgeons only constitute 2.4 percent of the total number of surgeons at the remaining hospital, implying that it is unlikely that the surgeon mix has

\footnotetext{
${ }^{32}$ The population registers contain detailed information on type of education. We identify surgeons as individuals who have completed their medical education specializing in surgery or other surgery related specialties like anesthesia or emergency care.
} 
changed to any dramatic extent after the closures. ${ }^{33}$ Even so, we can compare the characteristics of the surgeons who transferred to nearby hospitals to those of already existing surgeons at these hospitals. In the remaining rows of panel A of Table 5, we see that the labor earnings of surgeons transferring within the same region are higher than the labor earnings of surgeons that stay on, perhaps implying that more experienced surgeons are more likely to leave the closing hospital. However, since the average earnings of transferring surgeons are significantly lower than the average earnings of surgeons at the remaining hospitals, where operation volumes increase, there is nothing to suggest that the productivity of the surgeons that transfer is higher than the average productivity of the already existing surgeons. If anything, the opposite is more likely to be the case, since transferring surgeons are about the same age on average but have lower earnings. The main message from this exercise is that changes in the composition of surgeons are unlikely to explain our estimates.

Another way of testing for potential changes in staff composition is to estimate the direct impact of the closure of a cancer clinic on the number of surgeons employed at the remaining hospitals. ${ }^{34}$ If the increase is negligible, we would be less concerned about picking up changes in staff composition in our estimates. This is indeed what we find, as shown in column 3 of Table 3. A closure does not lead to any significant increase in the number of surgeons in the remaining hospitals. This finding is well in line with the observation that transferring surgeons only constitute 2.4 percent of all surgeons at remaining hospitals. These results also suggest that each individual surgeon has to take on more patients and, hence, that there is scope for learning at the individual level. We will return to this question when we discuss individual versus organizational learning below.

\subsection{Distance}

Shutting down a cancer clinic also means changing the distance to the nearest clinic for some patients. Even though the distance to a clinic should be less important for the outcome of cancer surgery - which is normally planned months in advance - we investigate whether changes in distance, implied by the closures, affect our results. For this, we merge detailed geographical information from Statistics Sweden on the place of residence of each patient

\footnotetext{
${ }^{33}$ In panel B, we examine the transfer of surgeons three years before a closure. During these years, only six percent of all the surgeons at the hospitals which shut down a cancer clinic three years later transferred to another hospital within the region. Hence, this result reinforces the conclusion that there were only limited excess transfers of surgeons following the cancer clinic closures.

${ }^{34}$ Note that any additional surgeons recruited do not necessarily have to come from other nearby shut down cancer clinics. By focusing directly on the number of new surgeons recruited, we can include any surgeons, irrespective of where they were recruited from.
} 
in our sample down to the level of a single block. Together with geographical data on all hospitals, this allows us to calculate the exact distance to each hospital. As we only have geographical data for the working age population, i.e. for individuals younger than 65, we proxy hospital distance for older patients using the average distance to the hospital for younger patients living in the same municipality.

In panel B of Table 4 we present the IV estimates including hospital distance (in kilometers) as a control variable in the model. We use two different measures of distance; distance to the treating hospital (reported in column 2 of the table) and distance to the nearest hos-

pital (reported in column 3). For comparison, column 1 reports the baseline estimate from Table 2 without controlling for hospital distance. As the point estimates for the volume effect are similar in all three specifications, we conclude that changes in the distance to hospital do not affect our results.

\subsection{Technology and queues}

If the inflow of additional patients to remaining cancer clinics also affects the organizational structure of the clinics, but not necessarily the hospital's organizational structure, the volume estimates might partly capture the impact of such organizational responses. We investigate two such potentially important mechanisms; changes in the type of surgical procedures performed (e.g., from more advanced and time-consuming procedures to simpler and quicker ones) and changes in waiting times.

To evaluate whether surgeons change their choice of surgical procedure as a consequence of the increase in patient inflow, we use information on the invasiveness of the surgery. Specifically, we use that partial mastectomies are less invasive but require more time than full or radical mastectomies. Also, prostatectomies can either be performed using the more invasive open retropubic surgery or via the more time-consuming, but minimally invasive, laparoscopic procedure. We estimate our IV model separately for each type of cancer using as outcome an indicator variable for whether the surgery was performed using the less invasive procedure. The results presented in panel $\mathrm{C}$ of Table 4 show no significant effects of the closures on the choice of procedure.

Another important technology is robot-assisted surgery. This technology also relates to scale effects, since besides learning, our estimated volume effects could in principle also arise from the utilization of more advanced technology that allow for scale economics. Note that scale effects are likely to be of less importance in advanced cancer surgery compared to other more standardized procedures. In the end, successful cancer surgery hinges to a large 
extent on the skills of the individual surgeon. If, however, greater surgical volumes means that clinics can exploit scale economics - so that any fixed costs will be distributed over a greater number of procedures - the clinic could afford more expensive technology which could in turn potentially improve surgery outcomes. Here, we investigate potential scale effects by using complementary information on perhaps the most obvious candidate for such a technology; robot assisted surgery.

Surgery robots are expensive and advanced type of technology which could potentially lead to improved surgery outcomes. We conjecture that, if scale effects exist, one indication for their existence would be an increased usage of surgery robots in remaining hospital cancer clinics after a nearby cancer clinic closes. In our sample, robots are only used in the treatment of prostate cancers and we estimate the probability that a cancer surgery is being performed with the assistance of a surgery robot both for the aggregated sample and separately for the relevant surgery types, using our preferred IV specification. ${ }^{35}$ The results are reported panel $\mathrm{D}$ of Table 4 and no significant increase in the probability of using a robot after a nearby clinic closes.

We look for signs of increased waiting times as volume increase by examining whether the average age of patients is affected by the additional patient inflow. If waiting times increase, we expect to see a higher average age of the patients at the time they undergo surgery. ${ }^{36}$ Panel E of Table 4 reports the results from re-estimating our preferred IV-model using patient age at surgery as outcome. The point estimate is insignificant and close to zero and hence do not indicate that patients are treated at a later (or earlier) stage due to increased workload. Hence, we conclude that neither selection in surgery procedures and technology nor increased waiting times are likely explanations for the volume-quality pattern we document in this paper. ${ }^{37}$

\footnotetext{
${ }^{35} \mathrm{On}$ average about five percent of all prostate cancer operations in our sample are performed with the assistance of a robot.

${ }^{36}$ Note, however, that, if anything, we would expect a higher age at surgery to be associated with lower survival, meaning that our estimated effect would be biased downwards.

${ }^{37}$ In addition, we have looked for changes in patient characteristics by replacing our main outcome variable, survival, with various socioeconomic and demographic factors. If clinics respond to an increase in volumes by prioritizing certain patient groups, we would expect to see an effect of volumes on the characteristics of the patients treated. We obtain no signs of this, however, when studying the income or the level of education of the patients treated as a function of volume.
} 


\section{$7 \quad$ Extensions and mechanisms}

We have so far documented that greater surgical volumes lead to improved surgical quality outcomes in terms of both increased survival prospects and fewer post-surgery complications among treated cancer patients. We have also ruled out a number of alternative explanations for our findings. In this section, we further examine the mechanism(s) and potential heterogeneity behind the estimated effects.

\subsection{Effect dynamics and learning}

In the section above, we studied the impact of current volumes on current outcomes. Below we study the effect dynamics within our empirical framework in more detail by investigating whether learning-by-doing persists over time, i.e. whether cumulative experience matters. To this end, we re-estimate our preferred specification from the last column of Table 2 and instrument the cumulated volume over one, two, and three years using the current and lagged closure status during the previous one, two and three years as instruments.

The results from this exercise are given in panel A of Table 6. First-stage F-statistics are reported for both the joint inclusion of all instruments and for each instrument separately. While the joint inclusion of the instruments is always highly significant, the three-year lagged instrument is somewhat weak, resulting in more imprecise estimates. Nevertheless, the estimated volume effects indicate important quality effects from cumulated volume. This result hence suggests that cumulative experience may have an additional impact on current surgical quality above and beyond the immediate experience acquired by the surgeon.

To further investigate the relationship between current and cumulative experience and surgical quality we include both current volumes and cumulated volumes as two separate explanatory variables in panel $\mathrm{B}$ of Table 6 . While the standard errors are high we see an interesting pattern from the point estimates reported in the table; as experience is accumulated over several years, the estimated proportion of the effect of current experience diminishes in relation to the effect of cumulated experience. This effect pattern is expected in a situation where learning from experience is, at least partially, kept and not forgotten over time, see e.g., Benkard (2000).

\subsection{Complexity of the surgery}

Next we study whether learning is more rapid for complex than for simple tasks. We investigate this possibility by estimating the volume effects separately for each type of cancer, 
making use of the fact that breast cancer surgery is generally considered a less complicated procedure than prostate and colorectal cancer surgery. This is also visible from the significantly higher average four-year mortality rate for the latter two types of cancer, as compared to breast cancer. If the effect of volume is smaller for breast cancer surgery, this is consistent with a learning interpretation. The results from this exercise is presented in Table 7 where the results show a positive, but insignificant (due to decreased sample sizes) volume effect for all three types of surgical procedures. Even if imprecisely estimated, the lower point estimate for breast cancer surgery - compared to colorectal and prostate cancer surgery indicates a positive relationship between complexity and learning. This finding is expected if learning is more rapid for more advanced tasks.

\subsection{Non-linear effects}

We have so far focused on linear volume effects, where our IV estimate captures a weighted average effect for hospitals of different sizes. Non-linear effects are hence difficult to investigate using this strategy. In order to analyze non-linearities, we instead use a hospital fixed-effects specification and rely on within-hospital variation over time to estimate the volume effects. In this way, we are able to specify a more flexible model by dividing volume into volume bins of twenty and to estimate separate effects for each bin. We estimate

$$
y_{i h s t}=\lambda_{t}+\lambda_{h}+\lambda_{s}+\text { volume }_{h t}^{\text {bin }} \gamma_{b i n}+X_{i} \beta+\epsilon_{i h s t}
$$

where volume hin $_{\text {in }}$ is a set of indicator variables for each volume bin. The estimated coefficient vector, $\gamma_{b i n}$, normalized so that the coefficient for the first volume bin is zero, is plotted in Figure 5 along with a local polynomial smoothed line. The figure reveals interesting nonlinearities of the volume effect. Specifically, the volume gradient is high at low volumes, diminishes over the volume distribution and reaches an empirical "learning threshold" for yearly hospital volumes of over 140 procedures after which there are practically no volume effects left in our data. As a large proportion of hospitals in our data operates below the threshold of 140 surgical procedures, this result lends some support to the idea that the concentration of cancer clinics may have a substantial effect on the quality of cancer surgery in Sweden. 


\subsection{Individual or organizational learning}

To what extent do our estimated learning effects reflect experience embodied in individual surgeons and to what extent do they reflect experience obtained at the level of the organization? This question is closely related to the individual vs. firm-specific human capital dichotomy in the labor economics literature. In our application, this distinction would mean that important sources of productivity are lost as surgeons leave a hospital if individual human capital is the driving force behind the learning effects.

While an increase in the number of operations per surgeon following the closure of a nearby cancer clinic means that there is potential for learning at the individual level, and organizational learning might operate simultaneously. In order to separate individual from organizational learning in our data, we therefore follow the ideas of Levitt et al. (2012), who argue that if organizational learning-by-doing is important, learning should be the same in organizations with high and low employee turnover. The intuition is simple; if the entire organization learns from experience, then the fact that employees are constantly replaced in high turnover organizations should not affect the relationship between volume and quality whereas, if experience is mainly embodied in individual employees, we should observe less learning in organizations with a high turnover.

We test the turnover hypothesis using supplementary information from employment records, which allows us to compute each surgeon's tenure. Based on average surgeon tenure, we divide hospitals into groups of low and high turnover, and subsequently estimate the fixed-effects model from the previous section separately for each hospital group. The result, shown in Figure 6, clearly shows that the volume effects are mainly driven by the low turnover clinics, consistent with a mechanism where the learning effects are mainly driven by the experience of individual surgeons. As suggested by the graph, there is no evidence of a positive relationship between volume and survival for hospitals with a high turnover. This is in great contrast to the line showing the corresponding relationship for hospitals with a low turnover; here we see a rapidly increasing survival rate as volumes increase, which levels off at about 140 procedures, consistent with the results shown in Figure 5. The results are different, however, in that the magnitude of the effect is much greater in hospitals with a low turnover. In sum, these results suggest that learning mainly is embodied in individual surgeons. 


\subsection{Production costs}

Finally, besides improving patient health outcomes, it is also important for health care authorities to know whether health care production costs are affected by learning-by-doing. One important source of hospital costs is the length of the hospital admissions associated with surgery. Increased learning might reduce costs for a hospital due to shorter admission spells as the organization becomes more efficient at performing surgery. We analyze this by estimating our IV model using information on the number of days each patient stays in hospital in conjunction with surgery as the outcome. From column 4 of Table 3 we can see that the number of days spent in hospital does not change significantly when volume

increases. We conclude that this important aspect of health care production costs is not affected by increased efficiency from learning to any important extent.

\section{Conclusions}

This paper documents a causal relationship between production volumes and the quality of advanced cancer surgery using data on more than 100,000 treatment episodes in Swedish public hospitals. We find that an increase in surgical volumes increases survival rates and leads to fewer post-surgical complications. The effect is greater at the lower end of the volume distribution and for more complex procedures, consistent with a learning-by-doing hypothesis in which experience of treating highly heterogeneous patients plays a fundamental role in the learning process. We show that the effects are not driven by selective referrals or self-selection, changes in the patient population, changes in surgical procedures or technology, or by organizational changes at the hospital level.

Our paper contributes to several strands of literature; first, our findings relate to the medical literature on the operation volume-outcome nexus. By exploiting the specific features of the public health care system in Sweden, we are able to overcome some of the empirical difficulties that earlier studies have struggled with. In contrast to the U.S. health care sector, where market structure - and thus hospital volumes - is an endogenous outcome of a competitive process, the institutional context of the Swedish health care sector provides us with variations in hospital volumes that are not driven by such forces. Instead, the closure of cancer clinics, generating large shifts in surgical volumes, is driven by political and bureaucratic considerations that we show are unrelated to underlying population health and cancer morbidity.

Next, our findings relate to the general literature on learning-by-doing and productivity 
growth. We contribute to the small amount of literature that provides causal evidence of learning effects and the specific mechanisms through which it operates. In contrast to the focus on learning in predominantly manual manufacturing industries of earlier literature, we provide evidence of rapid learning in a highly skilled context with high stakes. Moreover, we focus on quality improvements, such as survival rates, subsequent surgery and re-admissions, whereas most of the earlier literature has focused narrowly on production costs.

Finally, our results have implications for the organization of health care in publicly provided health care systems. Most previous studies on the volume-outcome nexus in the health care sector have taken place in the context of a competitive system where competition effects and determinants of hospital size are interconnected in complicated ways. Our results are also in contrast to some of the recent findings in the literature on hospital mergers. Gaynor et al. (2012a), for instance, find that mergers do not lead to any positive effects on quality outcomes in the British NHS. It is important to note that the literature on hospital mergers usually focuses on mergers of entire hospitals, whereas we focus on one particular activity where there is every reason to believe that mergers can lead to rapid learning. When entire hospitals merge, there is an increase in the production of all kinds of operations, including those where there is no scope for learning, and those in which volumes may exceed some upper threshold where quality may instead decline. Moreover, and as suggested by Gaynor et al. (2012a), hospital mergers reduce competition, which may have a negative impact on quality outcomes. In the Swedish public health care sector, such competition effects can be ruled out.

Our findings support recent organizational changes in the Swedish health care system (and in other countries) where mergers in specific areas, such as certain complicated types of surgery and transplantations, have recently been implemented with the aim of improving quality (Socialstyrelsen, 2005). We find that many cancer clinics operate at volume levels where there is substantial scope for learning, suggesting that policy makers can improve patient outcomes by encouraging mergers and the consolidation of cancer surgery. One way of accomplishing such changes is to enforce minimum volume thresholds that clinics are not allowed to operate below. Such thresholds have already been called for by researchers and policy-makers alike (Epstein, 2002; Shahian and Normand, 2003). The results obtained in this paper lend some support in favor of such policies. 


\section{References}

Acemoglu, D. and Finkelstein, A. (2008). Input and Technology Choices in Regulated Industries: Evidence from the Health Care Sector. Journal of Political Economy, 116(5):837880.

Angrist, J. and Krueger, A. (2001). Instrumental Variables and the Search for Identification: From Supply and Demand to Natural Experiments. Journal of Economic Perspectives, 15(4):69-85.

Arrow, K. (1962). The Economic Implications of Learning by Doing. Review of Economic Studies, 29(3):155-173.

Bandiera, O., Barankay, I., and Rasul, I. (2007). Incentives for Managers and Inequality among Workers: Evidence from a Firm-Level Experiment. Quarterly Journal of Economics, 122(2):729-773.

Bandiera, O., Barankay, I., and Rasul, I. (2009). Social Connections and Incentives in the Workplace: Evidence from Personnel Data. Econometrica, 74(4):1047-94.

Benkard, L. (2000). Learning and Forgetting: The Dynamics of Aircraft Production. American Economic Review, 90(4):1043-1054.

Birkmeyer, J., Stukel, T., Siewers, A., Goodney, P., Wennberg, D., and Lucas, F. (2003). Surgeon Volume and Operative Mortality in the United States. New England Journal of Medicine, 349(22):2117-2127.

Bloom, N., Eifert, B., Mahajan, A., McKenzie, D., and Roberts, J. (2013). Does Management Matter? Evidence from India. Quarterly Journal of Economics, 128:1-51.

Bloom, N., Propper, C., Seiler, S., and van Reenen, J. (2011). The Impact of Competition on Management Quality: Evidence from Public Hospitals. Discussion Paper 983, CEP.

Clemens, J. and Gottlieb, J. (2014). Do Physicians' Financial Incentives Affect Treatment Patterns and Patient Health? Forthcoming in American Economic Review.

Croxson, B., Propper, C., and Perkins, A. (2001). Do Doctors Respond to Financial Incentives? UK Family Doctors and the GP Fundholder Scheme. Journal of Public Economics, $79: 375-398$. 
Currie, J., Farsi, M., and MacLeod, B. (2005). Cut to the Bone?: Hospital Takeovers and Employment Contracts. Industrial and Labor Relations Review, 58(3):471-494.

Currie, J., Gruber, J., and Fischer, M. (1995). Physician Payments and Infant Mortality: Evidence from Medicaid Fee Policy. American Economic Review, 85(2):106-111.

Cutler, D. M. (2008). Are We Finally Winning the War on Cancer? Journal of Economic Perspectives, 22(4):3-26.

Darr, E. D., Argote, L., and Epple, D. (1995). The Acquisition, Transfer, and Depreciation of Knowledge in Service Organizations: Productivity in Franchises. Management Science, 41(11):1750-1762.

Dranove, D. and Lindrooth, R. (2003). Hospital Consolidation and Costs: Another Look at the Evidence. Journal of Health Economics, 22(6):983-997.

Epstein, A. (2002). Volume and Outcome - It is Time to Move Ahead. The New England Journal of Medicine, 346(15):1161-1164.

Farley, D. E. and Ozminkowski, R. (1992). Volume-Outcome Relationships and in Hospital Mortality: The Effect of Changes in Volume over Time. Medical Care, 30(1):77-94.

Ferlay, J., Steliarova-Foucher, E., Lortet-Tieulent, J., Rosso, S., Coebergh, J. W., Comber, H., Forman, D., and Bray, F. (2013). Cancer Incidence and Mortality Patterns in Europe: Estimates for 40 Countries in 2012. European Journal of Cancer, 49(6):1374-403.

Gaynor, M. (2006). What Do We Know About Competition and Quality in Health Care Markets? Working Paper 12301, NBER.

Gaynor, M., Laudicella, M., and Propper, C. (2012a). Can Governments do it Better? Merger Mania and Hospital Outcomes in the English NHS. Journal of Health Economics, $31: 528-543$.

Gaynor, M., Moreno-Serra, R., and Propper, C. (2011). Competition Could Substantially Benefit Healthcare. British Medical Journal, 343.

Gaynor, M., Moreno-Serra, R., and Propper, C. (2012b). Can Competition Improve Outcomes In UK Health Care? Lessons From the Past Two Decades. Journal of Health Services Research \& Policy, 17:49-54. 
Gaynor, M., Rebitzer, J., and Taylor, L. J. (2004). Physician Incentives in Health Maintenance Organizations. Journal of Political Economy, 112(4):915-931.

Gaynor, M., Seider, H., and Vogt, W. (2005). The Volume-Outcome Effect, Scale Economies, and Learning-by-Doing. The American Economic Review (Papers and Proceedings), $95(2): 243-247$.

Gowrisankaran, G., Ho, V., and Town, R. (2006). Causality, Learning and Forgetting in Surgery. mimeo 17608, University of Minnesota.

Halm, E. A., Lee, C., and Chassin, M. R. (2002). Is Volume Related to Outcome in Healthcare? A Systematic Review and Methodological Critique of the Literature. Annals of Internal Medicine, 137(6):511-520.

Hamilton, B. and Hamilton, V. (1997). Estimating Surgical Volume-Outcome Relationships Applying Survival Models: Account for Frailty and Hospital Fixed Effects. Health Economics, 6(4):383-395.

Hamilton, B. and Ho, V. (1998). Does Practice Make Perfect? Examining the Relationship between Hospital Surgical Volume and Outcomes for Hip Fracture Patients in Quebec. Medical Care, 36(6):892-903.

Hamilton, B., Nickerson, J. A., and Owan, H. (2003). Team Incentives and Worker Heterogeneity: An Empirical Analysis of the Impact of Teams on Productivity and Participation. Journal of Political Economy, 111(3):465-497.

Harrison, T. D. (2011). Do Mergers Really Reduce Costs? Evidence from Hospitals. Economic Inquiry, 49:1054-1069.

Ho, V. and Hamilton, B. (2000). Hospital Mergers and Acquisitions: Does Hospital Consolidation Harm Patients? Journal of Health Economics, 19:767-791.

Hossain, T. and List, J. A. (2009). The Behavioralist Visits the Factory: Increasing Productivity Using Simple Framing Manipulations. Working paper 15623, NBER.

Hughes, R., Garnick, D., Luft, H., McPhee, S., and Hunt, S. (1988). Hospital Volume and Patient Outcomes. The Case of Hip Fracture Patients. Medical Care, 26(11):1057-1067.

Jovanovic, B. and Nyarko, Y. (1995). A Bayesian Learning Model Fitted to a Variety of Empirical Learning Curves. Brookings Papers on Economic Activity, Microeconomics, 1:247-305. 
Kahn, J., Ten Have, T., and Iwashyna, T. (2009). The Relationship between Hospital Volume and Mortality in Mechanical Ventilation: An Instrumental Variable Analysis. Health Services Research, 44(3):862-879.

Kessler, D. and McClellan, M. (2000). Is Hospital Competition Socially Wasteful? Quarterly Journal of Economics, 115(2):577-615.

Kizer, K. (2003). The Volume-Outcome Conundrum. New England Journal of Medicine, 349(22):2159-2161.

Larsson Taghizadeh, J. (2009). Are Client Concerns Invisible and Weak in Sweden? About Protest Movements and their Influence on the County Council's Policy. Master thesis, Department of Political Science, Uppsala University.

Lazear, E. P. (2000). Performance Pay and Productivity. American Economic Review, 90(5):1346-1361.

Levitt, S. D., List, J. A., and Syverson, C. (2012). Toward an Understanding of Learning by Doing: Evidence from an Automobile Assembly Plant. Working paper 18017, NBER.

Lindbom, A. (2013). Waking up the Giant? Hospital Closures and Electoral Punishment in Sweden. mimeo, Department of Political Science, Uppsala University.

Lucas, R. E. (1988). On the Mechanics of Economic Development. Journal of Monetary Economics, 22(1):3-42.

Luft, H. S., Hunt, S., and Maerki, S. (1987). The Volume-Outcome Relationship: PracticeMakes-Perfect or Selective-Referral Patterns? Health Services Research, 22(2):157-182.

Lundberg, E. (1961). Produktivitet och Räntabilitet. Norstedt \& Söner, Stockholm.

Norton, E. C., Garfinkel, S. A., McQuay, L. J., Heck, D. A., Wright, J. G., Dittus, R., and Lubitz, R. M. (1998). The Effect of Hospital Volume on the In-Hospital Complication Rate in Knee Replacement Patients. Health Services Research, 33(5):1191-1210.

Propper, C., Burgess, S., and Gossage, D. (2008). Competition and Quality: Evidence from the NHS Internal Market 1991-9. Economic Journal, 118(525):138-170.

Propper, C., Burgess, S., and Green, K. (2004). Does Competition Between Hospitals Improve the Quality of Care? Hospital Death Rates and the NHS Internal Market. Journal of Public Economics, 88:1247-1272. 
Propper, C., Sutton, M., and Whitnall, C. (2010). Incentives and Targets in Hospital Care: Evidence from a Natural Experiment. Journal of Public Economics, 94:318-335.

Propper, C. and Van Reenen, J. (2010). Can Pay Regulation Kill? Panel Data Evidence on the Effect of Labor Markets on Hospital Performance. Journal of Political Economy, $118: 222-273$.

Shahian, D. and Normand, S. (2003). The Volume-Outcome Relationship: From Luft to Leapfrog. Annals of Thoracic Surgery, 75(3):1048-1058.

Socialstyrelsen (2005). Nationell Samordning av Rikssjukvården. Technical report, Socialstyrelsen. Proposition to the Parliament 2005/06:73.

Socialstyrelsen (2007). Cancervården i Sverige. Kvalitet, Struktur och Aktuella Utmaningar. Technical Report 2007, Socialstyrelsen.

Thompson, P. (2001). How Much Did the Liberty Shipbuilders Learn? New Evidence for an Old Case Study. Journal of Political Economy, 109(1):103-137.

Thompson, P. (2012). The Relationship Between Unit Cost and Cumulative Quantity and the Evidence for Organizational Learning-by-Doing. Journal of Economic Perspectives, $26(3): 203-224$.

Thornton, R. and Thompson, P. (2001). Learning from Experience and Learning from Others: An Exploration of Learning and Spillovers in Wartime Shipbuilding. American Economic Review, 91(5):1350-1368.

Tsai, A., Votruba, M., Bridges, J., and Cebul, R. (2006). Overcoming Bias in Estimating the Volume-Outcome Relationship. Health Services Research, 41(1):252-264.

Volpp, K., Ketcham, J., Epstein, A., and Williams, S. (2005). The Effects of Price Competition and Reduced Subsidies for Uncompensated Care on Hospital Mortality. Health Services Research, 40(4):1056-1077.

Wright, T. (1936). Factors Affecting the Cost of Airplanes. Journal of Aeronautical Sciences, $3(4): 122-128$. 


\section{Tables and figures}

\section{FIGURE 1.}

Surgical volume vs. cancer survival
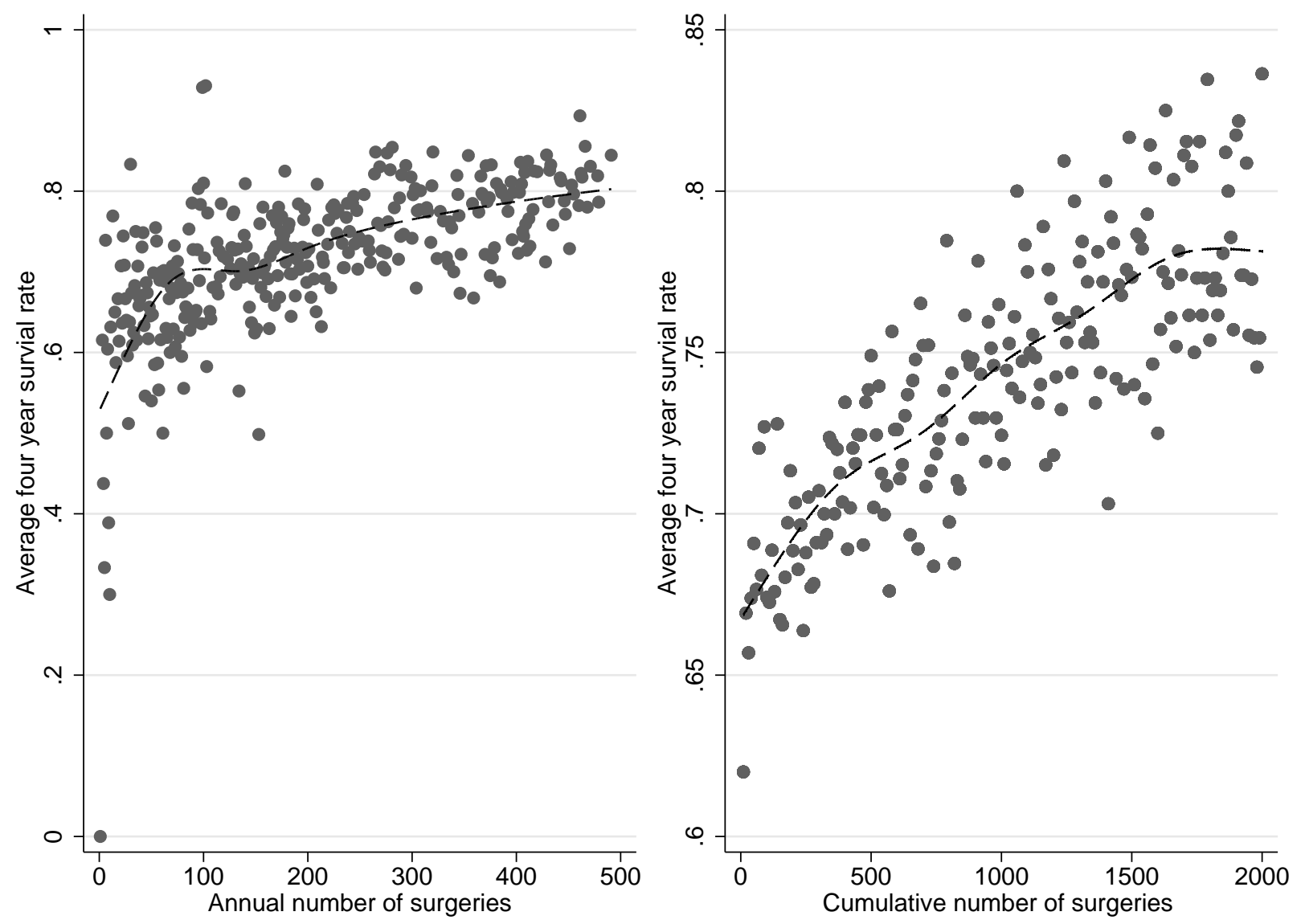

Note: The left figure relates the hospital annual number of cancer surgeries to four-year survival. The right figure plots the cumulative number of surgeries performed at each hospital since 1998 in the sample vs. four-year survival. The dots represent surgical volume averages in bins of ten. 
FIGURE 2.

Hospital closures and surgical volume in remaining regional hospitals

(a)

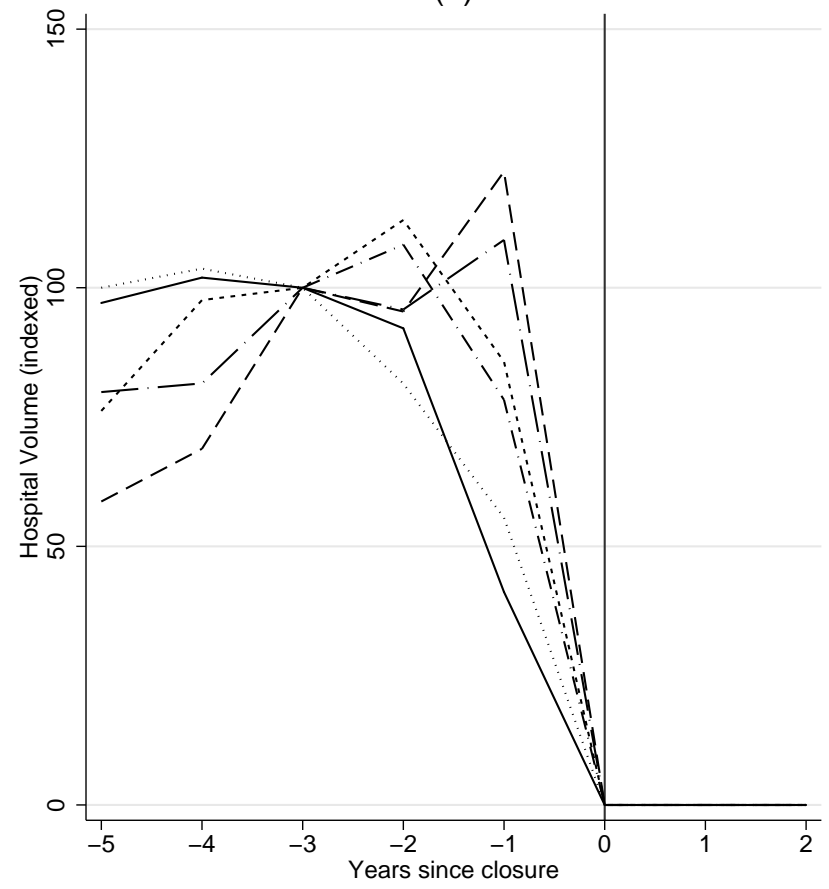

(b)

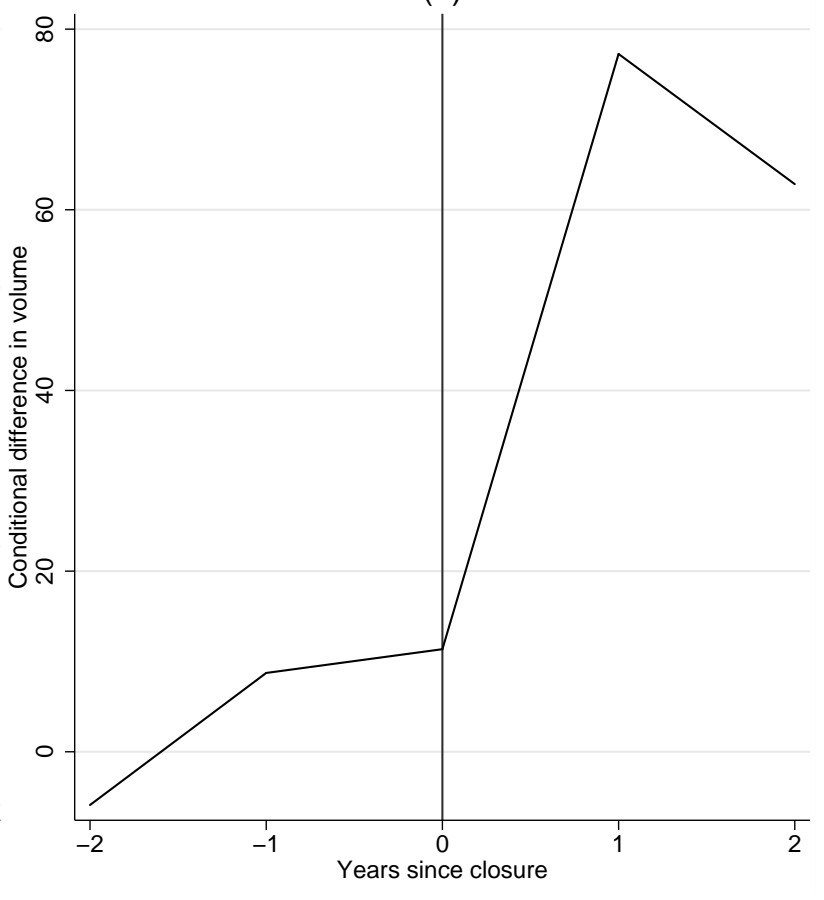

Note: The left figure shows annual number of surgeries (index volume three years before closure $=100$ ) for each closing cancer. The right figure presents the difference in average hospital volume for hospitals in regions with closures and hospitals in regions without any closures, adjusted by hospital and calendar time fixed effects. Unaffected regions are used as a potential closure for each year a change occurred in an affected region. 
FIGURE 3.

Health and socioeconomic statistics in regions with and without closures

(a) Cancers

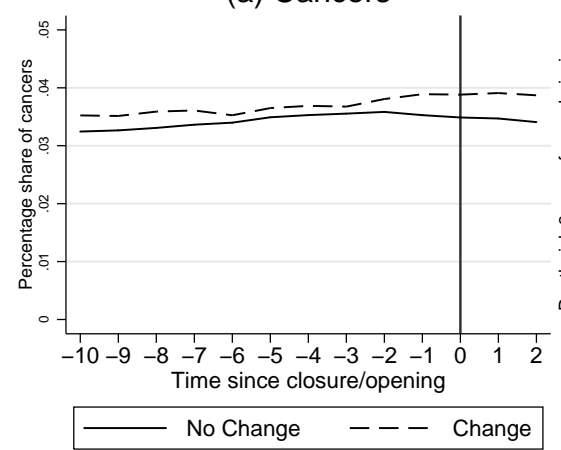

(d) Morbidity

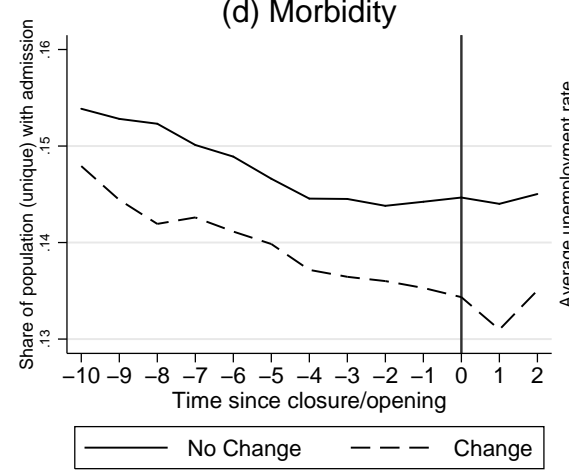

(b) Mortality

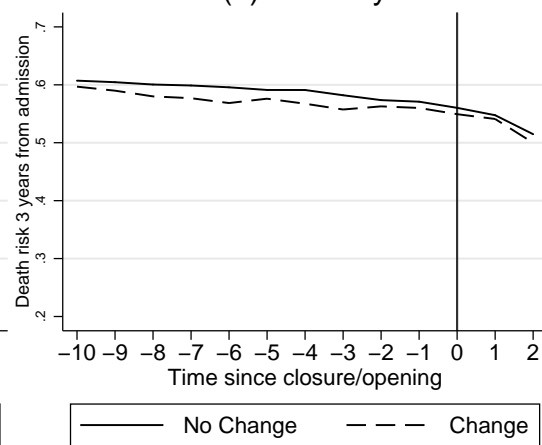

(e) Unemployment (c) Population

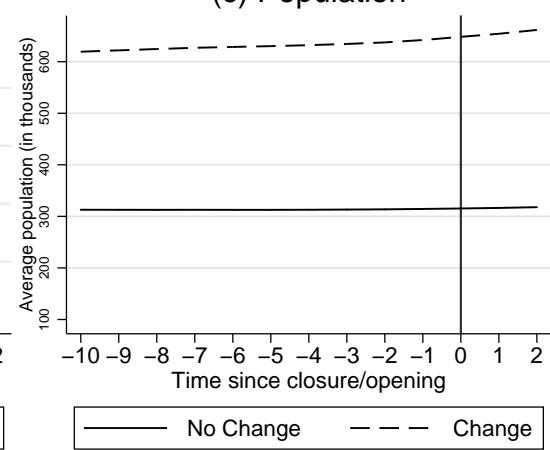

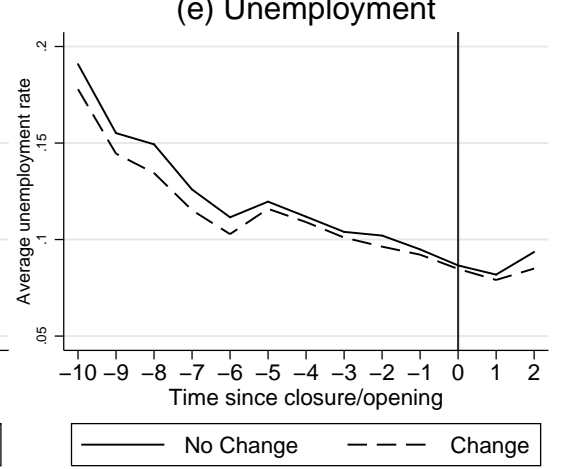

Note: Unconditional health, population and economic statistics for regions with closures (dashed line) and without any closures (solid line). Unaffected regions are used as a potential opening or closure for each year a change occurred in an affected region. 
FIGURE 4.

Adjusted health and socioeconomic statistics in regions with and without closures

(a) Cancers
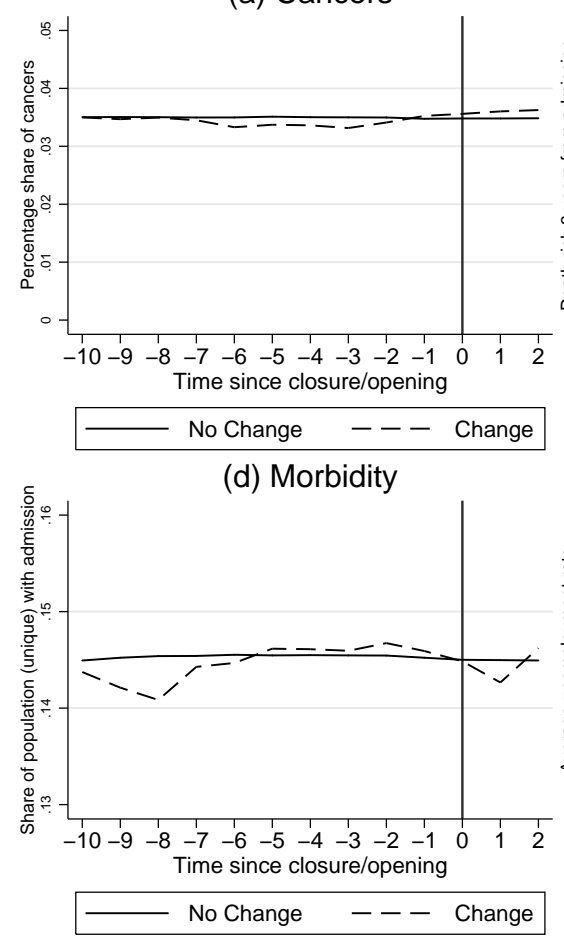

(b) Mortality

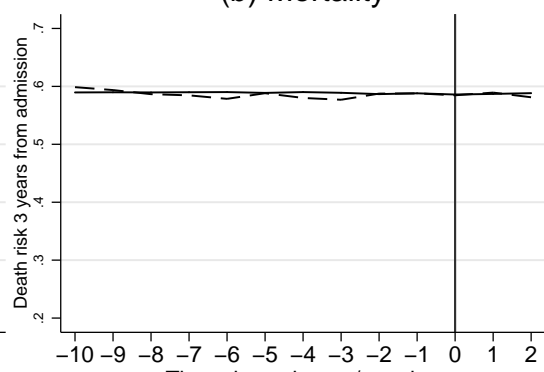

Time since closure/opening

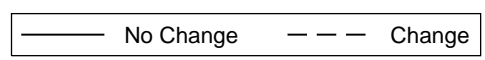

(e) Unemployment

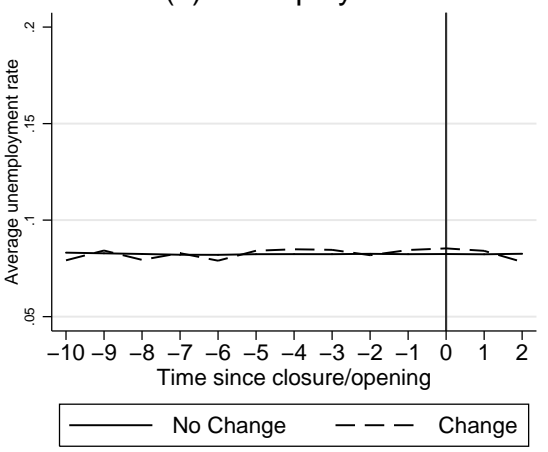

(c) Population

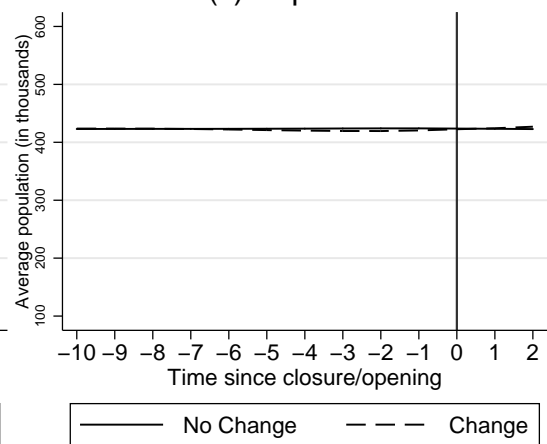

Note: Conditional health, population and economic statistics (adjusted for calendar year and hospital fixed-effects and regional linear trends) for regions with closures (dashed line) and without any closures (solid line). Unaffected regions are used as a potential opening or closure for each year a change occurred in an affected region. 
FiguRE 5.

Non-linear volume effects on four-year post-surgery survival

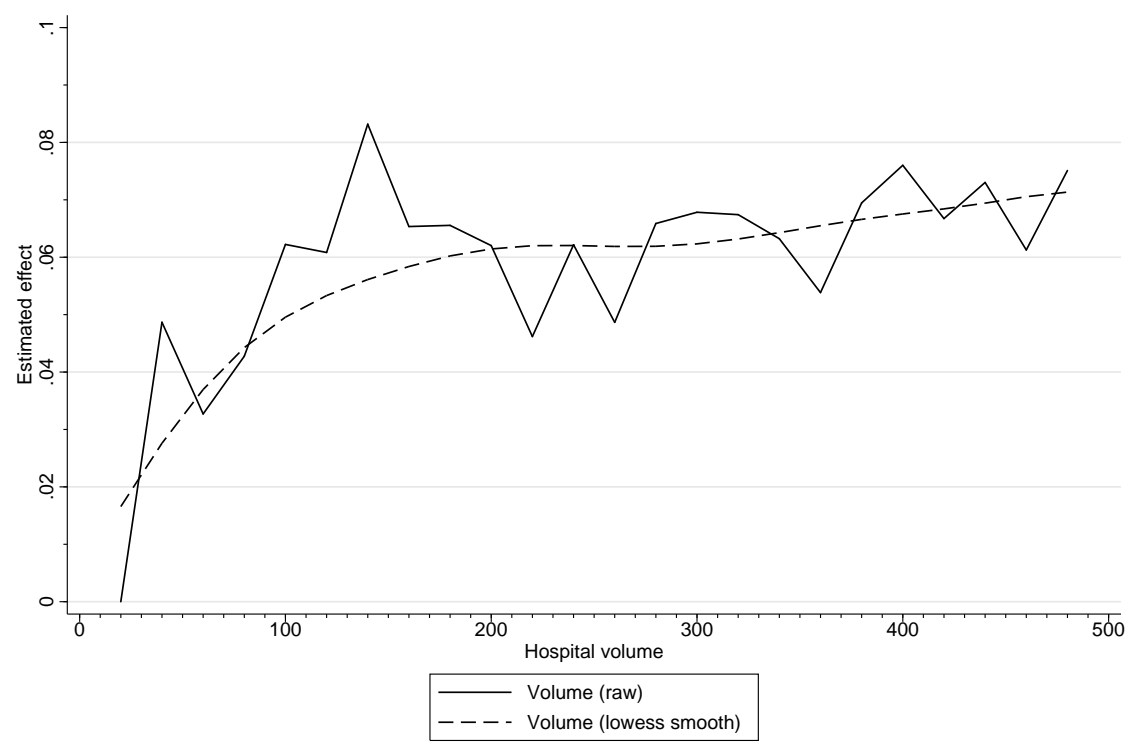

Note: The figure plots the estimated coefficients of surgical volume on four-year post-surgery survival from a fixed-effects regression model including regional, calendar year and surgery fixed effects, see equation 3 in the results section. The non-linear volume effects are estimated by including dummy variables for every twenty volume bin constructed from the analysis data, using the first volume bin as the reference category. The solid line pertains to the non-smoothed relationship while the dashed line is obtained by running locally weighted regressions of the estimated volume coefficients on the corresponding dependent variable. 
FIGURE 6.

Non-linear volume effects on four-year post-surgery survival probability by high and low hospital average turnover

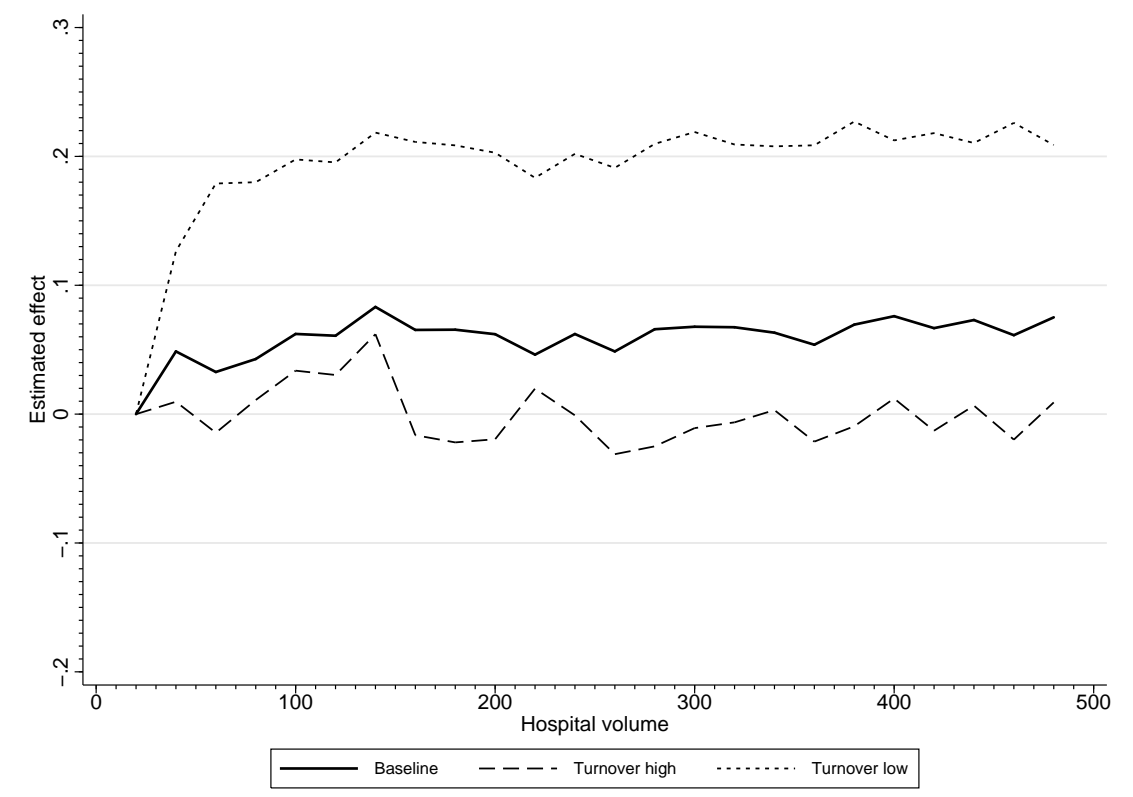

Noте: The figure plots the estimated coefficients of surgical volume on four-year post-surgery survival from a fixed-effects regression model including regional, calendar year and surgery fixed effects. The non-linear volume effects are estimated by including dummy variables for each twenty volume bin constructed from the analysis data, using the first volume bin as reference category. Each line corresponds to a different sample category; the solid line is for the full sample, and the dashed (dotted) is for hospitals with less (more) than median staff turnover. 
TABLE 1.

Sample statistics

\begin{tabular}{lrccc}
\hline & Frequency & $\begin{array}{c}\text { Fraction of } \\
\text { sample }\end{array}$ & Mean age & $\begin{array}{c}\text { y year death } \\
\text { rate }\end{array}$ \\
\hline Full sample & 109,761 & 1.00 & 66.26 & 0.39 \\
1998 & 9,707 & 0.09 & 66.38 & 0.58 \\
1999 & 9,914 & 0.09 & 66.73 & 0.55 \\
2000 & 10,450 & 0.10 & 66.69 & 0.51 \\
2001 & 10,800 & 0.10 & 66.39 & 0.47 \\
2002 & 11,225 & 0.10 & 66.63 & 0.43 \\
2003 & 11,778 & 0.11 & 66.22 & 0.38 \\
2004 & 12,119 & 0.11 & 65.87 & 0.33 \\
2005 & 12,568 & 0.11 & 66.02 & 0.28 \\
2006 & 12,492 & 0.11 & 65.83 & 0.25 \\
2007 & 8,708 & 0.08 & 65.99 & 0.21 \\
Breast cancer & 52,363 & 0.48 & 62.03 & 0.28 \\
Partial mastectomy & 25,953 & 0.24 & 59.75 & 0.18 \\
Full mastectomy & 10,022 & 0.09 & 66.22 & 0.37 \\
Radical mastectomy & 16,399 & 0.15 & 63.08 & 0.39 \\
Intestine cancer & 30,626 & 0.28 & 70.90 & 0.56 \\
Right hemi-colectomy & 10,903 & 0.10 & 73.15 & 0.58 \\
Left hemi-colectomy & 2,086 & 0.02 & 70.28 & 0.53 \\
Sigmoidectomy & 5,199 & 0.05 & 70.22 & 0.55 \\
Rectum resection (LAR/TME) & 7,342 & 0.07 & 68.29 & 0.47 \\
Hartmann's operation & 1,679 & 0.02 & 74.41 & 0.78 \\
Abdominoperineal resection & 3,473 & 0.03 & 69.03 & 0.59 \\
Prostate cancer & 26,772 & 0.24 & 69.22 & 0.43 \\
Retropubic prostatectomy & 11,525 & 0.11 & 62.64 & 0.09 \\
Endoscopic prostatectomy & 2,245 & 0.02 & 61.53 & 0.03 \\
Transurethal resection & 10,015 & 0.09 & 75.79 & 0.78 \\
Orchidectomy & 2,920 & 0.03 & 78.59 & 0.89 \\
\hline Nor Tre & 515 & & \\
\hline
\end{tabular}

Note: The definition of the different types of surgery is discussed in section three of the paper and classified according to the Nordic Classification of Surgical Procedures, NCSP: Partial mastectomy (HAB40), full mastectomy (HAC20), radical mastectomy (HAC22), right hemicolectomy (JFB30), left hemicolectomy (JFB43), sigmoidectomy (JFB46), rectum resection (LAR/TME) (JGB00), Hartmann's operation (JGB10), abdominoperineal resection (JGB30), retropubic prostatectomy (KEC00), endoscopic prostatectomy (KEC01), transurethal resection (KED22) and orchidectomy (KFC10). 
TABLE 2.

Estimates of the effect of surgical volume on four-year post-surgery survival

\begin{tabular}{|c|c|c|c|c|c|c|}
\hline & $\begin{array}{c}(1) \\
\text { OLS }\end{array}$ & $\begin{array}{l}(2) \\
\text { FS }\end{array}$ & $\begin{array}{c}(3) \\
\text { Restricted } \\
\text { IV }\end{array}$ & $\begin{array}{l}(4) \\
\text { Main } \\
\text { IV }\end{array}$ & $\begin{array}{c}(5) \\
\text { With } \\
\text { controls }\end{array}$ & $\begin{array}{c}(6) \\
\text { Case-mix } \\
\text { adjusted }\end{array}$ \\
\hline $\log$ (volume) & $\begin{array}{c}0.057^{* * *} \\
(0.005)\end{array}$ & & $\begin{array}{c}0.070 \\
(0.043)\end{array}$ & $\begin{array}{c}0.055^{* * *} \\
(0.018)\end{array}$ & $\begin{array}{c}0.055^{* * *} \\
(0.017)\end{array}$ & $\begin{array}{c}0.048^{* * *} \\
(0.018)\end{array}$ \\
\hline Closure & & $\begin{array}{c}0.167^{* *} \\
(0.077)\end{array}$ & & & & \\
\hline \multicolumn{7}{|c|}{ Socioeconomic characteristics } \\
\hline Age & & & & & $\begin{array}{c}0.018^{* * *} \\
(0.001)\end{array}$ & $\begin{array}{c}0.018^{* * *} \\
(0.001)\end{array}$ \\
\hline Age squared & & & & & $\begin{array}{c}-0.000 * * * \\
(0.000)\end{array}$ & $\begin{array}{c}-0.000 * * * \\
(0.000)\end{array}$ \\
\hline Female & & & & & $\begin{array}{c}0.059 * * * \\
(0.005)\end{array}$ & $\begin{array}{c}0.060 * * * \\
(0.005)\end{array}$ \\
\hline Immigrant & & & & & $\begin{array}{c}0.002 \\
(0.003)\end{array}$ & $\begin{array}{c}0.003 \\
(0.004)\end{array}$ \\
\hline Unknown origin & & & & & $\begin{array}{l}-0.012 \\
(0.009)\end{array}$ & $\begin{array}{l}-0.009 \\
(0.010)\end{array}$ \\
\hline High school & & & & & $\begin{array}{c}0.013 * * * \\
(0.003)\end{array}$ & $\begin{array}{c}0.013^{* * * *} \\
(0.003)\end{array}$ \\
\hline College & & & & & $\begin{array}{c}0.023^{* * *} \\
(0.003)\end{array}$ & $\begin{array}{c}0.023^{* * * *} \\
(0.003)\end{array}$ \\
\hline Unknown educ. & & & & & $\begin{array}{c}-0.016^{*} \\
(0.009)\end{array}$ & $\begin{array}{c}-0.016^{*} \\
(0.009)\end{array}$ \\
\hline \multicolumn{7}{|l|}{ Previous admissions } \\
\hline One & & & & & $\begin{array}{c}0.005 \\
(0.004)\end{array}$ & $\begin{array}{l}0.006^{*} \\
(0.004)\end{array}$ \\
\hline Two & & & & & $\begin{array}{l}-0.003 \\
(0.005)\end{array}$ & $\begin{array}{c}-0.001 \\
(0.005)\end{array}$ \\
\hline Three & & & & & $\begin{array}{c}-0.014 * * * \\
(0.005)\end{array}$ & $\begin{array}{c}-0.013^{* * *} \\
(0.005)\end{array}$ \\
\hline Four & & & & & $\begin{array}{l}-0.006 \\
(0.007)\end{array}$ & $\begin{array}{c}-0.004 \\
(0.007)\end{array}$ \\
\hline More than four & & & & & $\begin{array}{c}-0.066^{* * *} \\
(0.005)\end{array}$ & $\begin{array}{c}-0.065^{* * * *} \\
(0.005)\end{array}$ \\
\hline \multicolumn{7}{|l|}{ Time since last admission } \\
\hline One to three years & & & & & $\begin{array}{c}0.039^{* * *} \\
(0.004)\end{array}$ & $\begin{array}{c}0.040^{* * *} \\
(0.004)\end{array}$ \\
\hline Four to six years & & & & & $\begin{array}{c}0.060 * * * \\
(0.004)\end{array}$ & $\begin{array}{c}0.061 * * * \\
(0.004)\end{array}$ \\
\hline Seven to nine years & & & & & $\begin{array}{c}0.068^{* * *} \\
(0.005)\end{array}$ & $\begin{array}{c}0.067^{* * * *} \\
(0.004)\end{array}$ \\
\hline More than nine years & & & & & $\begin{array}{c}0.060^{* * *} \\
(0.018)\end{array}$ & $\begin{array}{c}0.062^{* * *} \\
(0.018)\end{array}$ \\
\hline Time FE & $\checkmark$ & $\checkmark$ & $\checkmark$ & $\checkmark$ & $\checkmark$ & $\checkmark$ \\
\hline Hospital FE & & $\checkmark$ & $\checkmark$ & $\checkmark$ & $\checkmark$ & $\checkmark$ \\
\hline Linear trends & & $\checkmark$ & $\checkmark$ & $\checkmark$ & $\checkmark$ & $\checkmark$ \\
\hline Mean survival & 0.78 & 0.78 & 0.78 & 0.78 & 0.78 & 0.78 \\
\hline Observations & 109,761 & 109,761 & 109,761 & 109,761 & 109,761 & 105,028 \\
\hline
\end{tabular}

Note: Outcome is four year survival after cancer surgery. Model (5) and (6) also include type of surgery fixed effects. In columns (2) and (3) the closure instrument is specified as a dummy variable and in columns (3)-(6) as a set of dummy variables. The last column reports estimates from using the case-mix restricted sample excluding everyone with a designated hospital which at some point is either opened or closed. Reference categories are male, native, below high school, no previous admissions and admission the same year. Standard errors are clustered at the hospital level. ${ }^{*}, * *$ and ${ }^{* * *}$ denote statistical significance at the 10,5 and 1 percent levels. 
TABle 3.

Estimates of the effect of surgical volumes on additional outcomes

(1)

New cancer

surgery

$\begin{array}{cc}-0.034^{* *} \\ \log (\text { volume }) & (0.017)\end{array}$

(2)

Re-admission

$$
0.08
$$

105,028

(3)

Number of surgeons

$-0.041$

Mean of outcome

Observations

2.204

\subsection{2 \\ 105,028}

Note: IV estimates using the case-mix adjusted sample (excluding everyone with a designated hospital which at some point is either opened or closed). New cancer surgery (re-admission) is an indicator for the event of subsequent cancer surgery (hospitalization) within three (one) year(s) after the initial cancer surgery. Number of surgeons is measured as the total number of surgeons in the hospital in which the patient was treated for cancer and time in hospital is measured as the number of days of the spell in hospital at the time of cancer surgery. All models include calendar time, hospital, surgery fixed-effect and regional linear trends. Standard errors are clustered at the hospital level. * ${ }^{* *}$ and *** denote significance at the 10,5 and 1 percent levels. 
TABLE 4.

Organizational changes, distance to hospital, technology and queues

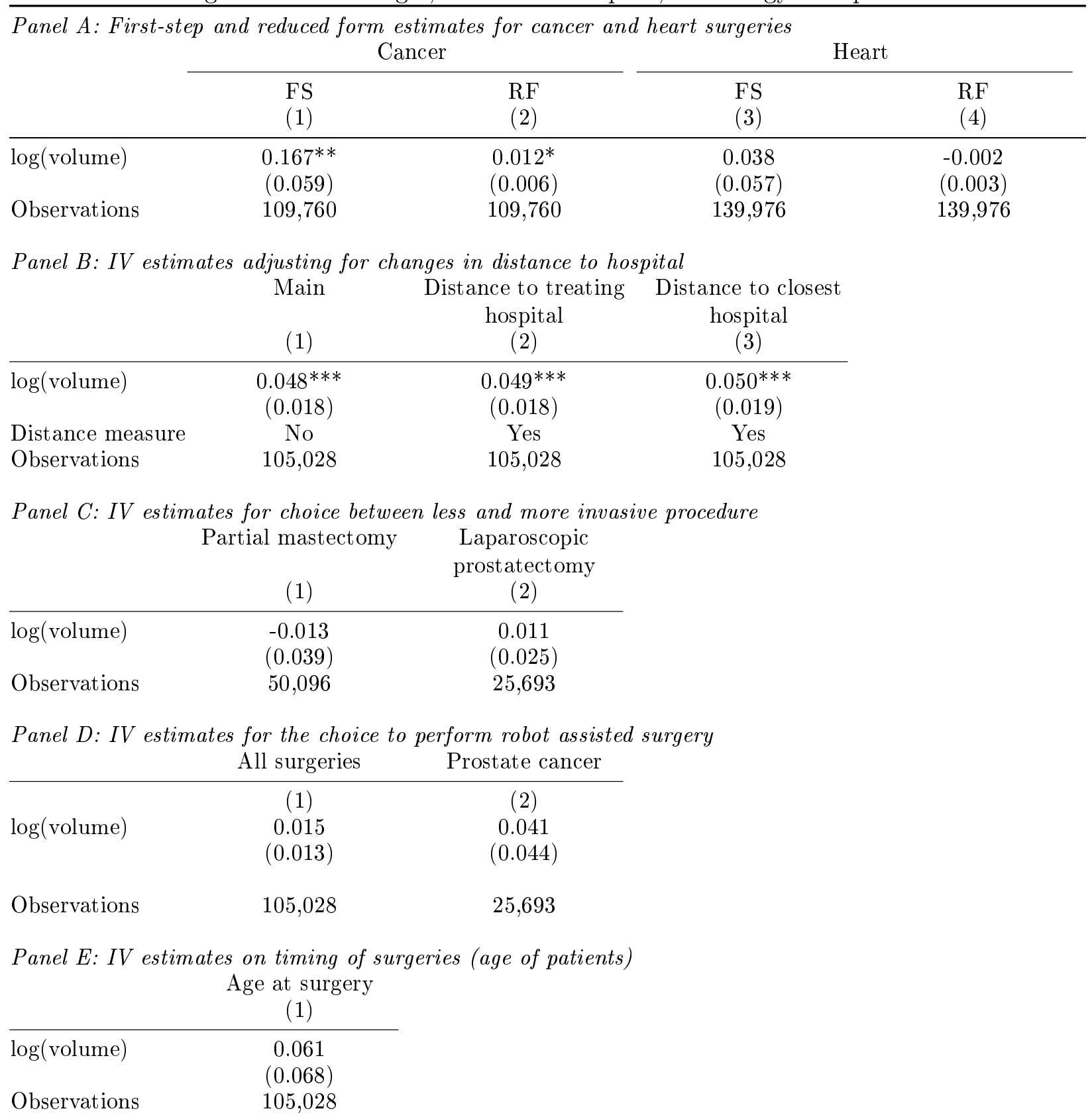

Note: Panel A reports first-stage and reduced-form estimates of surgical volume from the cancer and heart surgery samples in which the cancer clinic closure instrument is used for both samples (see the results section). In Panel B, column (1) reproduces the results from our preferred specification in column (6) of Table 2 and columns (2) and (3) additionally include as control variable the distance to i) the treating hospital and ii) the closest hospital. Panel C reports IV estimates using the subsample of breast (prostate) cancer surgery in column $(1)((2))$ and an indicator variable for whether the performed surgery was coded as a partial mastectomy (laparoscopic prostatectomy) as outcome variable. In panel D the outcome is an indicator for the decision to perform robot assisted surgery. Panel E reports IV estimates using patient age at surgery as outcome. For all specifications in the table, standard errors are clustered at the hospital level and *,** and *** denote significance at the 10, 5 and 1 percent levels. 
TABLE 5.

Statistics for surgeons at remaining and closing cancer clinics who remain or transfer within or outside closure regions

Panel A: Statistics one year after closure

Surgeons at closed clinics one year before closure

\begin{tabular}{|c|c|c|c|}
\hline Stay & $\begin{array}{c}\text { Transfer } \\
\text { within region }\end{array}$ & $\begin{array}{c}\text { Transfer } \\
\text { outside } \\
\text { region }\end{array}$ & $\begin{array}{c}\text { Remaining } \\
\text { hospitals }\end{array}$ \\
\hline
\end{tabular}

\begin{tabular}{lcccc}
\hline \% of surgeons at "closed" & 0.69 & 0.18 & 0.13 & \\
& & & & 45.4 \\
Age & 45.8 & 46.0 & 46.5 & 634,123 \\
Labor earnings & 606,278 & 611,720 & 581,665 & 0.36 \\
Females \% & 0.49 & 0.20 & 0.30 & 0.74 \\
Married \% & 0.63 & 0.64 & 0.48 &
\end{tabular}

Panel B: Statistics two years before closure

Surgeons at closed clinics three years before closure

Stay Transfer Transfer Remaining

within region outside hospitals

$\begin{array}{llll}\% \text { of surgeons at "closed" } & 0.88 & 0.06 & 0.06\end{array}$

Age

45.8

45.0

47.2

Labor earnings

536,698

520,714

534,520

43.6

Females \%

0.37

0.57

0.27

586,588

Married \%

0.62

0.71

0.60

0.36

0.66

Nоте: Statistics for who were employed at hospitals where the cancer clinic remained open and surgeons employed at hospitals where the cancer clinic closed but who stayed, transferred within or outside the region respectively. Panel A and panel B report sample means for surgeons one and three year before the closures. Labor earnings are measured on an annual basis in SEK (one SEK is approximately equal to $0.15 \mathrm{USD}$ ). 
TABLE 6.

Estimates of the effect of cumulated surgical volume on four-year post-surgery survival

\begin{tabular}{|c|c|c|c|}
\hline & $(1)$ & $(2)$ & $(3)$ \\
\hline $\log ($ current volume $)$ & $\begin{array}{c}0.048^{* * *} \\
(0.018)\end{array}$ & & \\
\hline $\log$ (cum. vol. last 2 years $)$ & & $\begin{array}{l}0.083^{*} \\
(0.046)\end{array}$ & \\
\hline $\log$ (cum. vol. last 3 years $)$ & & & $\begin{array}{c}0.082 \\
(0.068)\end{array}$ \\
\hline$F$ statistics First-stage & & & \\
\hline F-stat. Level & 199.1 & 23.8 & 25.0 \\
\hline F-stat. Lag 1 & & 14.5 & 34.2 \\
\hline F-stat. Lag 2 & & & 3.4 \\
\hline F-stat. All & 199.1 & 45.9 & 117.3 \\
\hline Observations & 105,028 & 95,802 & 86,272 \\
\hline Panel B: Cumulated and cu & lume & $(2)$ & $(3)$ \\
\hline $\log ($ current volume $)$ & $\begin{array}{c}0.048^{* * *} \\
(0.018)\end{array}$ & $\begin{array}{c}0.050^{* *} \\
(0.021)\end{array}$ & $\begin{array}{l}0.032^{*} \\
(0.017)\end{array}$ \\
\hline $\log$ (cum. vol. last 1 year $)$ & & $\begin{array}{c}0.021 \\
(0.059)\end{array}$ & \\
\hline $\log ($ cum. vol. last 2 years $)$ & & & $\begin{array}{c}0.050 \\
(0.048)\end{array}$ \\
\hline F statistics First-stage & & & \\
\hline Log volume & 199.1 & 183.7 & 220.4 \\
\hline Cumulated variable(s) & & 18.7 & 127.6 \\
\hline Observations & 105,028 & 95,802 & 86,272 \\
\hline
\end{tabular}

Note: IV estimates using the case-mix adjusted sample (excluding everyone with a designated hospital which at some point is either opened or closed). The outcome is four-year survival after cancer surgery. In column (1) the volume instrument is specified as a set of dummy variables indicating a closure in the region the same year while in columns (2) and (3) instruments for cumulative volume are both current and two (three) years lagged clinic closures. All models include calendar time, hospital, surgery fixed-effect and regional linear trends. First stage F-statistics are reported for all instruments both separately and jointly. Standard errors are clustered at the hospital level. ${ }^{*}, * *$ and ${ }^{* * *}$ denote significance at the 10,5 and 1 percent levels. 
TABLE 7.

Estimates of the effect of surgical volume on survival by complexity of the surgery

\begin{tabular}{lccc}
\hline & $\begin{array}{c}\text { Breast } \\
(1)\end{array}$ & $\begin{array}{c}\text { Colorectal } \\
(2)\end{array}$ & $\begin{array}{c}\text { Prostate } \\
(3)\end{array}$ \\
\hline $\log ($ volume $)$ & 0.017 & 0.066 & 0.059 \\
& $(0.020)$ & $(0.087)$ & $(0.051)$ \\
Mean survival rate & 0.86 & & 0.71 \\
First-stage F-stat. & 311.9 & 9.62 & 55.6 \\
Observations & 50,096 & 29,334 & 25,693 \\
\hline
\end{tabular}

NoтE: IV estimates using the case-mix adjusted sample (excluding everyone with a designated hospital which at some point is either opened or closed). Each column corresponds to the estimation results depending on the type of cancer. Outcome is four-year survival after cancer surgery. All models include calendar time, hospital, surgery fixed-effect and regional linear trends. Standard errors are clustered at the hospital level. ${ }^{*}, * *$ and ${ }^{* * *}$ denote significance at the 10,5 and 1 percent levels. 